\title{
E2F-4, a new member of the E2F transcription factor family, interacts with p107
}

\author{
Doron Ginsberg, ${ }^{1}$ Gino Vairo, ${ }^{1}$ Thomas Chittenden, ${ }^{1,3}$ Zhi-Xiong Xiao, ${ }^{1}$ Gangfeng Xu, ${ }^{1}$ \\ Karen L. Wydner, ${ }^{2}$ James A. DeCaprio, ${ }^{1}$ Jeanne B. Lawrence, ${ }^{2}$ and David M. Livingston ${ }^{1,4}$ \\ ${ }^{1}$ Dana-Farber Cancer Institute and Harvard Medical School, Boston, Massachusetts 02115 USA; ${ }^{2}$ Department of Cell Biology, \\ University of Massachusetts, Medical Center, Worcester, Massachusetts 01655 USA
}

The E2F family of transcription factors has been implicated in the regulation of cell proliferation, and E2F-binding sites are present in the promoters of several growth-regulating genes. E2F family members are functionally regulated, in part, by complex formation with one or more members of the nuclear pocket protein family, RB, p107, and p130. Pocket protein regulation of E2F likely contributes to normal cellular growth control. While the three cloned species of E2F, E2F-1, E2F-2, and E2F-3, are known to be targets of RB interaction, no E2F species has yet been shown to be a specific p107 or p130 target. Here, we describe the cloning of a new member of the E2F family, E2F-4, which forms heterodimers with a member(s) of the DP family and, unlike some family members, is present throughout the cell cycle and appears to be a differentially phosphorylated p107-binding partner. p107 binding not only can be linked to the regulation of E2F-4 transcriptional activity, but also to suppression of the ability of E2F-4 to transform an immortalized rodent cell line.

[Key Words: E2F; cell cycle; growth control; transcription; p107; transformation]

Received August 12, 1994; revised version accepted September 21, 1994.

The transcription factor E2F was originally identified as a cellular DNA-binding protein required for activation of the adenovirus E2A promoter (Kovesdi et al. 1986; Yee et al. 1987). The interaction of E2F with the sequence TTTCGCG, present twice in the E2 promoter, stimulates its transcription (Loeken and Brady 1989; Yee et al. 1989|. E2F sites were subsequently detected in the promoters of multiple growth-responsive and growth-promoting cellular genes, including c-myc, c-myb, N-myc, dihydrofolate reductase (DHFR), thymidine kinase (TK), thymidine synthetase, DNA polymerase $\alpha$, cyclin A, cyclin D1, and cdc2 (Blake and Azizkhan 1989; Hiebert et al. 1989, 1991; Thalmeier et al. 1989; Mudryj et al. 1990; Pearson et al. 1991; Dalton 1992; Nevins 1992; Herber et al. 1994; Phillip et al. 1994; Yamamoto et al. 1994). The E2F-binding site was shown to be involved in the activation of the c-myc, DHFR, TK, B-myb, and $c d c 2$ genes following serum stimulation (Blake and Azizkhan 1989; Mudrij et al. 1990; Dalton 1992; Means et al. 1992; Lam and Watson 1993). These observations suggest that E2F activity plays a role in fostering cell-cycle progression.

Regulation of E2F activity is achieved, in part, through its interaction with certain cellular proteins. The retinoblastoma susceptibility gene product (RB) binds directly

\footnotetext{
${ }^{3}$ Present address: Immunogen, Cambridge, Massachusetts 02139 USA. ${ }^{4}$ Corresponding author.
}

to certain E2F species and inhibits their ability to transactivate (Bagchi et al. 1991; Chellappan et al. 1991; Chittenden et al. 1991; Dalton, 1992; Hamel et al. 1992; Hiebert et al. 1992; Weintraub et al. 1992; Zamanian and La Thangue 1992). Furthermore, RB growth suppression activity in some assays correlates with its ability to interact with E2F (Qin et al. 1992). The RB-related protein, p107, forms two independent complexes with E2F. In one of them, cyclin A and cdk2 are also present, while cyclin $\mathrm{E}$ and cdk2 are present in the other (Cao et al. 1992; Devoto et al. 1992; Pagano et al. 1992; Shirodkar et al. 1992). E2F and a third pocket protein, pl30, form a complex analogous to the p107-E2F complex(es) (Cobrinik et al. 1993|. Where tested, pocket protein-binding results in suppression of the trans-activation function of an E2F target species. Individual pocket protein-E2F complexes appear and disappear at different times in the cell cycle (Shirodkar et al. 1992), and the available evidence suggests a model in which each has a specific set of transcriptional consequences that contribute to the regulation of cell cycle arrest/progression. Moreover, all of these pocket protein E2F-containing complexes can be dissociated by certain small DNA tumor virus oncoproteins, including adenovirus E1A, papovavirus large $\mathrm{T}$ antigen, and human papilloma virus E7 (for review, see $\mathrm{La}$ Thangue 1994), leading to the release of free E2F, which is believed to be the E2F species that trans-activates. 
Because each of these viral proteins also stimulates $G_{1}$ exit and this activity depends on its pocket protein-binding function (Moran 1993), these results further support the notion that E2F activation contributes to cell-cycle progression.

E2F-1 was cloned by virtue of its ability to bind RB (Helin et al. 1992; Kaelin et al. 1992; Shan et al. 1992). Soon after its cloning it became apparent that the term E2F signifies a family of transcription factors. Using peptide sequence from a protein, purified by E2F DNA chromatography, Girling et al. (1993) isolated a second E2Frelated cDNA, designated DP-1. Recent studies have shown that E2F-1 and DP-1 normally form heterodimers and that these heterodimers stimulate the DNA- and RB-binding action of E2F-1 (Bandara et al. 1993; Helin et al. 1993; Huber et al. 1993; Krek et al. 1993|. Using E2F-1 as a probe for low stringency library screening, two more E2F species, designated E2F-2 and E2F-3, were isolated (Ivey-Hoyle et al. 1993; Lees et al. 1993). In vivo, E2F-1, E2F-2, and E2F-3 all bind RB but do not form complexes with p107. A variety of evidence suggests that RB and p107 bind distinct E2F species (Chittenden et al. 1993; Dyson et al. 1993).

Here, we report the cloning of a new member of the

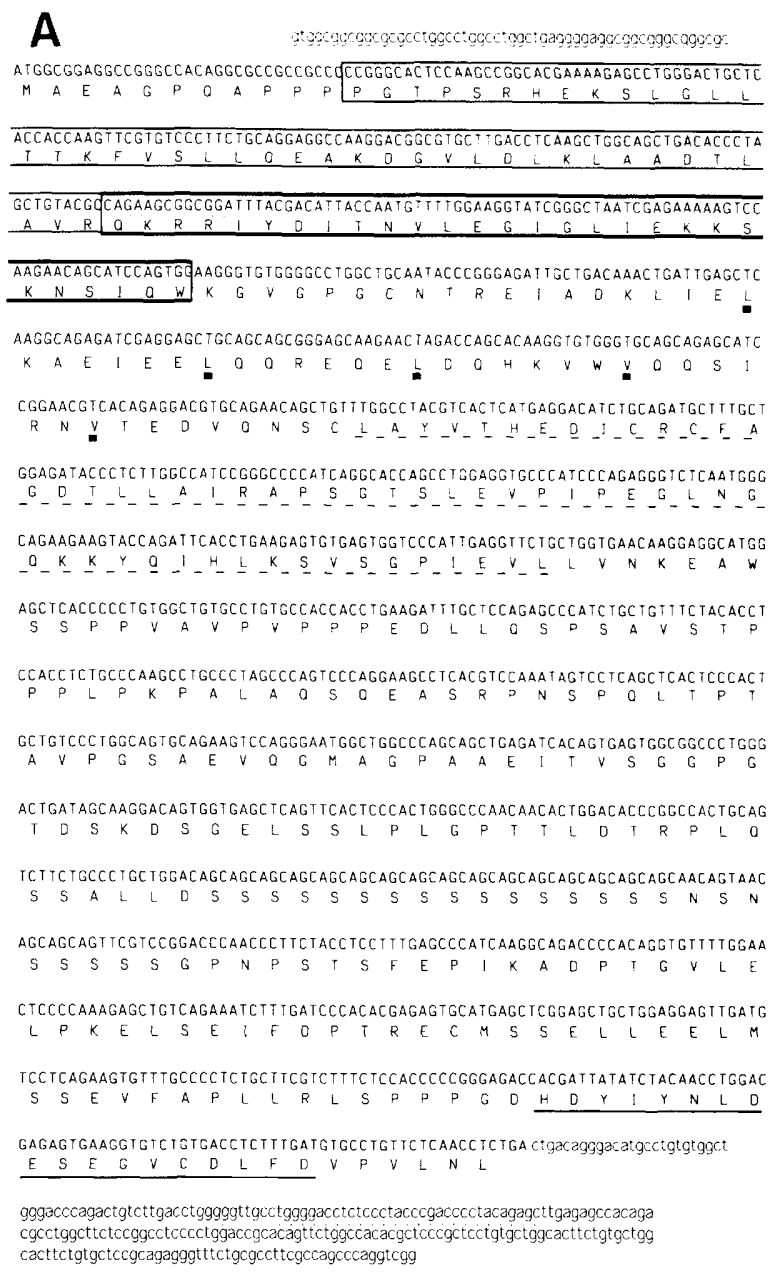

E2F family, E2F-4. By comparison with the existing E2F species, E2F-4 has certain unique structural and functional properties, among which is complex formation with p107 in vivo.

\section{Results}

\section{Isolation of cDNAs encoding E2F-4}

In search of new, human E2F cDNA species, polymerase chain reaction (PCR), primed by various degenerate oligonucleotides designed from the human E2F-1 sequence (Kaelin et al. 1992), was performed using mRNA templates derived from enriched human $\mathrm{T}$ lymphocytes. Various combinations of degenerate primers failed to yield new E2F cDNA molecules. However, when nondegenerate oligonucleotides corresponding to the sequence outlined in Figure 1A were used, they repeatedly gave rise to two DNA fragments, only one of which was of the expected size for E2F-1 cDNA. The two DNA fragments were subcloned into another vector for sequencing. The fragment resembling a segment of the E2F-1 cDNA in size corresponded to the predicted segment of E2F-1 cDNA. The other contained sequences that were similar,

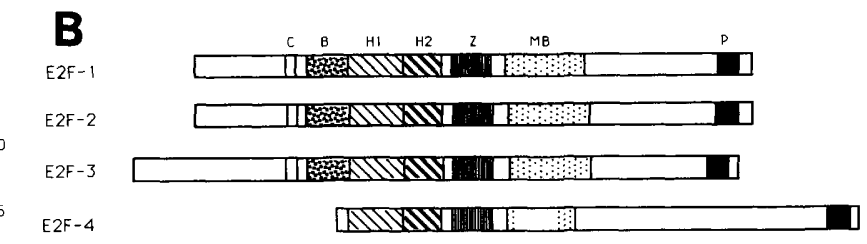

Figure 1. Human E2F-4 sequence. $\{A\}$ Nucleotide sequence of a cDNA encoding human E2F-4 and the predicted E2F-4 amino acid sequence. The numbers at right represent the nucleotide number in the coding sequence. The DNA-binding domain is marked by the light-lined ( $\mathrm{H} 1$ - low E2F sequence identity conservation) and dark-lined ( $\mathrm{H} 2$-high E2F sequence identity conservation) boxes. (D) The hydrophobic residues in the heptad repeat. The marked box (MB) and the pocket protein-binding domain are underlined by a broken and a solid line, respectively. The sequences to which the oligonucleotides, used in the PCR, annealed are underscored by a dotted line. $(B)$ Schematic representation of E2F-1, E2F-2, E2F-3, and E2F-4 sequences. The conserved regions are boxed: cyclin-binding domain $(\mathrm{C})$; basic do-

25) main (B); DNA-binding domain ( $\mathrm{H} 1$-low conservation and $\mathrm{H} 2$-high conservation sequence regions); heptad repeat $(\mathrm{Z})$; marked box $(\mathrm{MB})$; the RB family (pocket protein)-binding domain (P). 
but not identical, to those present in the DNA-binding domain of E2F-1, E2F-2, E2F-3.

This product was then used as a probe to screen $\lambda$ libraries prepared from HeLa (a human cervical carcinoma-derived cell line) and Nalm6 cells (a human pre-B leukemic cell line). One million plaques from each library were screened under high stringency conditions. Following plaque purification and in vivo excision, six positive cDNA molecules were isolated, five from the HeLa library and one from the Nalm6 library. Sequencing of the positive clones revealed a colinear sequence of 2100 nucleotides that contained an open reading frame (ORF), open at its $5^{\prime}$ end. From the imputed protein sequence beginning at the first methionine, a protein product of 411-416 amino acids was predicted (Fig. 1A). The reason for the variation in protein size will be discussed below. This ORF, present in three of these cDNA products, appears to encode a new, full-length E2F species, which we have termed E2F-4.

\section{E2F-4 structural features}

The overall identity between E2F-4 and E2F-1 is $27 \%$ at the amino acid sequence level. Not surprisingly, given the high degree of overall homology among all previously known E2F species (Lees et al. 1993), a significant degree of homology to E2F-2 and E2F-3 was also detected. The homology between E2F-4 and the other three proteins is especially evident in four subsegments of its sequence.

The first spans residues $12-81$ in E2F-4. This region corresponds to a segment of the E2F-1 DNA-binding domain, residues 102-196 of E2F-1 (Helin et al. 1992). The overall homology between E2F-1 and E2F-4 is $67 \%$ in this region, although it is more pronounced in the carboxy-terminal part of this segment $-89 \%$ over the 28 residues noted in Figure $1 \mathrm{~B}$, box $\mathrm{H} 2$. In contrast, there was only $50 \%$ homology in the amino-terminal 42 amino acids of this region (Fig. 1B, box $\mathrm{Hl}$ ).

Similar overall degrees of homology exist between E2F-4 and E2F-2, as well as E2F-4 and E2F-3, in the putative E2F-4 DNA-binding domain (Fig. 1B, boxes $\mathrm{H} 1+\mathrm{H} 21$. A second region of E2F-4 homology to the three previously known E2F species consists of a hydrophobic heptad repeat unit of 29 residues located immediately carboxy-terminal to the putative DNA-binding domain (Fig. 1B, box Z). As in the other E2F species, five hydrophobic residues, present at every seventh position in this segment, were detected. The intervening residues are mostly not conserved among the four E2F proteins that were analyzed (Fig. 1; Lees et al. 1993).

A third region of E2F-1, E2F-2, and E2F-3 homology (53\% homology among these proteins) has been termed the "marked box" (Lees et al. 1993). It spans residues 251-317 in E2F-1 and is of unknown function (Fig. 1B, $\mathrm{MB}$ ). In comparison, E2F-4 revealed limited homology to the others in this region. In comparison with E2F-1, for example, it was only detected within stretches of 5 and 15 residues located at the amino and carboxyl termini of the $\mathrm{MB}$ segment, respectively.
The fourth region of homology to E2F-1, E2F-2, and E2F-3 is located at its carboxyl terminus. In that region, E2F-4 contains a stretch of 18 residues that are $55 \%$ homologous to the analogous sequence of E2F-1. Similar homology was noted to the analogous sequences of E2F-2 and E2F-3 (50\% and 55\%, respectively). This short sequence constitutes the RB-binding domain of E2F-1 (Helin et al. 1992) and is likely the pocket protein-binding motif of E2F-2 and E2F-3, as well.

The new E2F species is also characterized by certain unique structural features. First, in E2F-1, E2F-2, and E2F-3 the DNA-binding domain is preceded by 121,130 , and 178 amino-terminal residues, respectively. This portion of these three proteins also contains two conserved regions. One is a stretch of basic amino acids that is adjacent to the DNA-binding domain, and the second, located more toward the amino terminus, is a sequence that mediates direct interaction with cyclin A in E2F-1 (Krek et al. 1994). In E2F-4, this entire region, including the cyclin-binding and the basic domains, is absent, and the DNA-binding domain begins at residue 13 of the protein sequence (Fig. 1B).

A second structural difference between E2F-4 and E2F1, E2F-2, and E2F-3 is the spacing between the MB and the region containing the acidic trans-activation domain within which the pocket protein-binding domain is imbedded. In E2F-1, E2F-2, and E2F-3 this spacing is very similar, 78, 62, and 59 residues, respectively. In E2F-4 the space between these regions is significantly larger, 149 residues. This increased spacing is partially attributable to another unique feature of E2F-4, a repeat of the triplet, CAG, which encodes a polyserine array. Similar CNG repeats are present in a number of other genes, and changes in their size have been correlated with a number of human disorders (Morell 1993).

\section{Polymorphic variations in the $(C A G)_{n}$ trinucleotide repeat of E2F-4}

The CAG repeat in the E2F-4-coding region varied in size in the few individual cDNAs isolated during the original cloning of E2F-4. Of the four cDNAs sequenced in this region, two contained $16 \mathrm{CAG}$ repeats, and the other two contained 13 and 11 repeats, respectively. Because of this variability, the repeat length was measured in a group of DNA samples using PCR with oligonucleotides flanking the CAG repeat region. All 55 samples analyzed yielded a PCR product corresponding to a DNA molecule containing 13 CAG repeats. In 7 of these samples, there was an additional band corresponding to DNA molecules containing $7,9,11,14$, or $16 \mathrm{CAG}$ repeats /data not shown|. This result suggested that the individuals whose DNAs yielded these bands are heterozygotes for E2F-4, that is, they carry two alleles with different numbers of CAG repeats, and the E2F-4 reading frame in the $(C A G)_{n^{-}}$ encoded region is maintained in all cases. Because E2F-4 containing 11 or 16 serines in the polyserine array functioned identically in DNA binding and trans-activation assays (see Fig. 3A,B, below), the significance of the existing variations is, at the moment, unclear. 


\section{Expression and cell cycle analysis of E2F-4}

A DNA fragment of E2F-4 cDNA was used to probe a Northern blot containing poly(A) RNA from various human tissues (Clontech). A complementary RNA species of $\sim 2.2 \mathrm{~kb}$ was present in all tissues tested, including heart, brain, placenta, lung, liver, skeletal muscle, kidney, and pancreas (data not shown).

In an attempt to determine the pattern of E2F-4 mRNA expression during the cell cycle, NIH-3T3 fibroblasts were growth-arrested by serum deprivation and allowed to resume growth following serum readdition. Their cell cycle state was monitored by FACS. As noted in Figure 2, A and B, E2F-4 mRNA was present in the growth-arrested state, and its abundance did not change significantly as cells moved into and through the cell cycle. Similar results were obtained with primary human $T$ cells (data not shown). This pattern of expression is significantly different from that of E2F-1 and DP-1 mRNA levels, which are cell-cycle controlled and are markedly up-regulated following serum stimulation (Fig. 2A; Kaelin et al. 1992; Slansky et al. 1993; Li et al. 1994). E2F-1 homologous RNA was detectable in $\mathrm{G}_{0}$ cells, although the bands were not intense (Fig. 2A,B). The intensity of the two fastest migrating bands increased dramatically 8-12 hr after serum stimulation. The DP-1
mRNA level was readily detected in growth-arrested cells, although it, too, increased at the same time as E2F-1 (Fig. 2A,B). Western blot analysis, using protein extracts of NIH-3T3 cells, which were similarly growth arrested and serum induced, indicated that the E2F-4 protein was also present in the growth-arrested cells and that its levels did not change significantly as cells resume growth (Fig. 2C). Interestingly, E2F-4 migrated as a heterogeneous set of bands $(\sim 57-64 \mathrm{kD})$, the basis for which is discussed below.

\section{E2F-4 binds to an E2F recognition site}

The specific DNA-binding activity of the newly cloned protein was tested. Specifically, we synthesized a glutathione $S$-transferase GST-E2F-4 fusion protein and then measured its ability to bind to an oligonucleotide corresponding to the E2F-binding site within the DHFR promoter (Shirodkar et al. 1992). As can be seen in Figure $3 \mathrm{~A}$, the fusion protein demonstrated clear oligonucleotide-binding activity in a bandshift assay. A wild-type, but not a mutant E2F site-containing oligonucleotide competed with the labeled probe for binding to the protein, implying that the interaction observed was specific for an intact E2F site. E2F-4 species with 11 and 16
Figure 2. Cell cycle analysis of E2F-4 expression. (A) Cell cycle analysis of E2F-4 mRNA abundance. NIH-3T3 cells were starved for $65 \mathrm{hr}$ in standard medium containing $0.5 \%$ BCS. Cells were then stimulated by the addition of $20 \%$ BCS and harvested at various times after serum addition for both FACS analysis and RNA extraction. Poly $(\mathrm{A})^{+}$-enriched RNA was obtained, and $7 \mu \mathrm{g}$ of each sample was subjected to Northern blot analysis using human E2F-4 cDNA as a probe. The Northern blot was then stripped and reprobed with cDNA of the acidic ribosomal phosphoprotein $\mathrm{PO}$, $36 \mathrm{~B} 4$, as a control for RNA loading, and with murine E2F-1 and murine DP-1 cDNAs. Time (in hours) after serum addition is indicated at the top. The cell cycle distribution of the cells under analysis is indicated at the bottom. $(B)$ Densitometric analysis of the results depicted in $A$. Autoradiographs presented in $A$ were quantitated by laser densitometry. The values obtained were normalized relative to the level of 36B4 gene expression and presented as the fold induction relative to the signal present at time zero (0). For E2F-1, where three bands were present (see text), the data reflect the major band corresponding in size to the previously reported murine E2F-1 mRNA (Li et al. 1994). (口) E2F-4; ( $\times$ ) E2F-1; (O) DP-1. (C) Cell cycle analysis of E2F-4 protein abundance. Whole-cell extracts were prepared from asynchronous cultures of human U937 cells and NIH-3T3 cells, that had been growth arrested and serum induced essentially as described in $A$. At the indicated times (hours) after serum addition, E2F-4 protein abundance was analyzed by Western blotting using anti-E2F-4 mAb GG22 as described in Materials and methods.
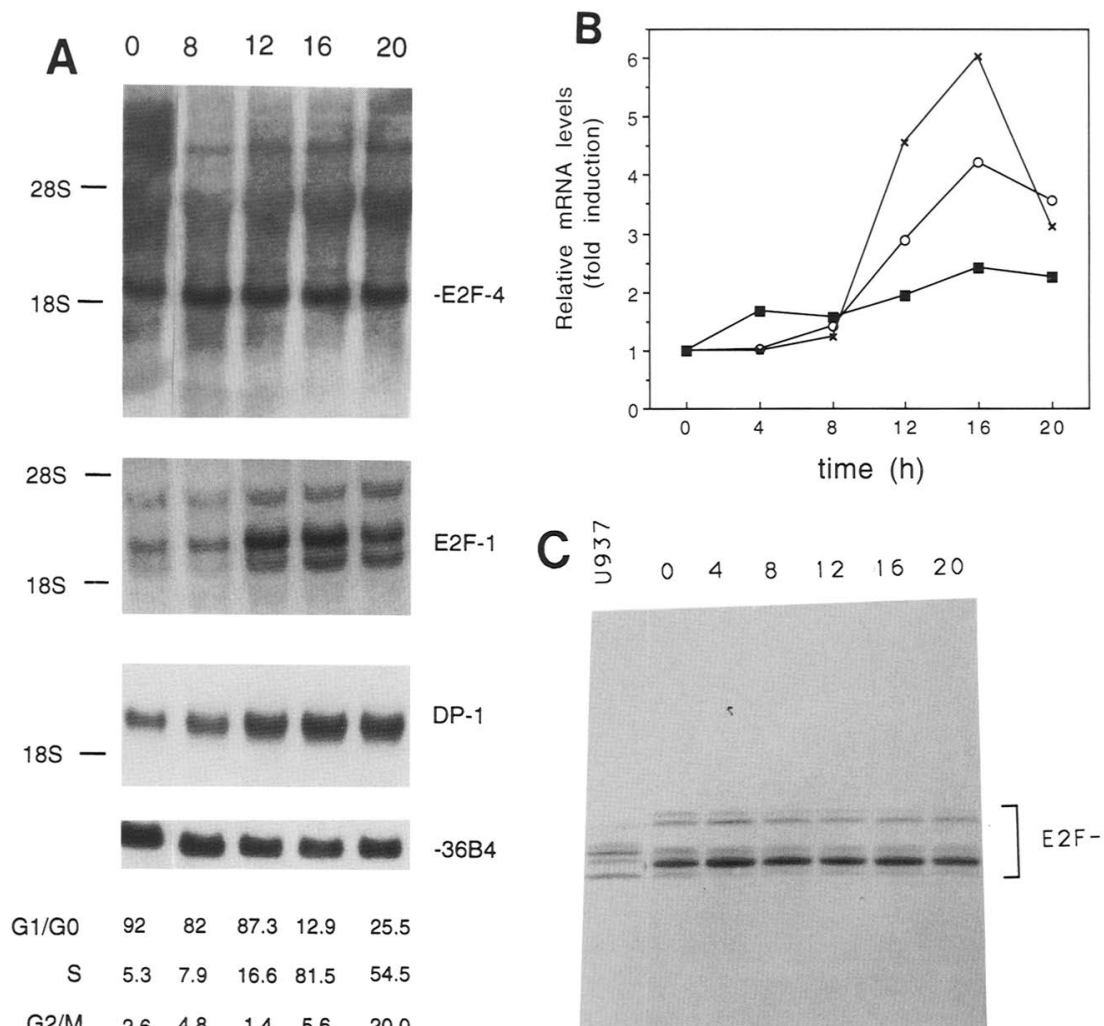

$\mathrm{G} 2 / \mathrm{M} \quad 2.6 \quad 4.8 \quad 1.4 \quad 5.6 \quad 20.0$

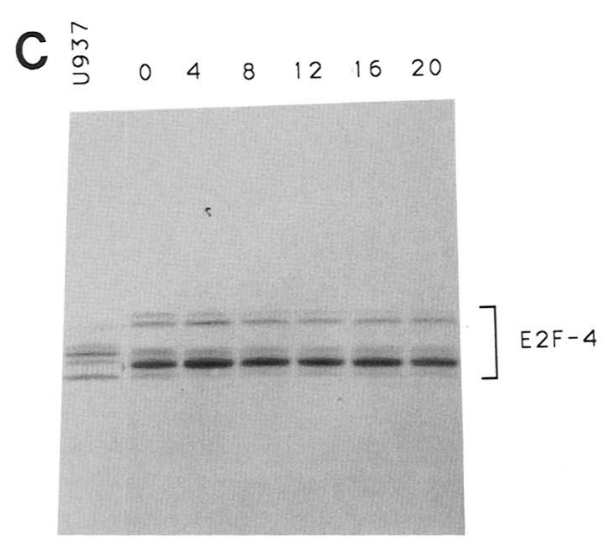

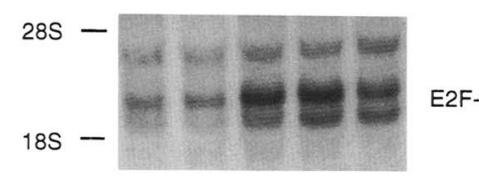




\section{A}

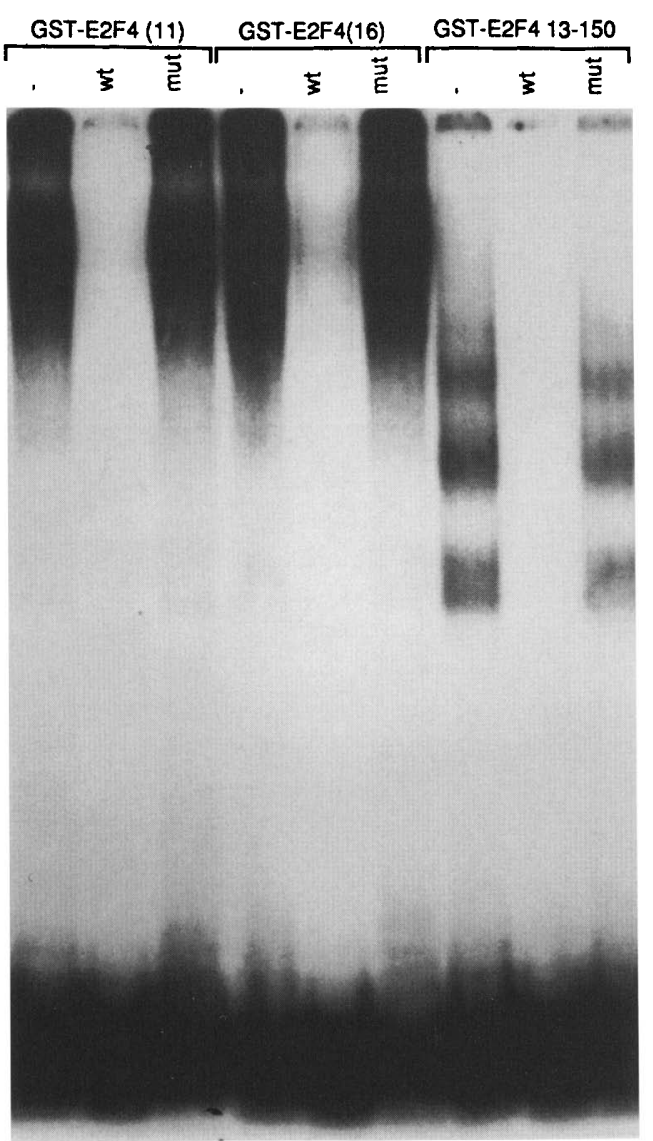

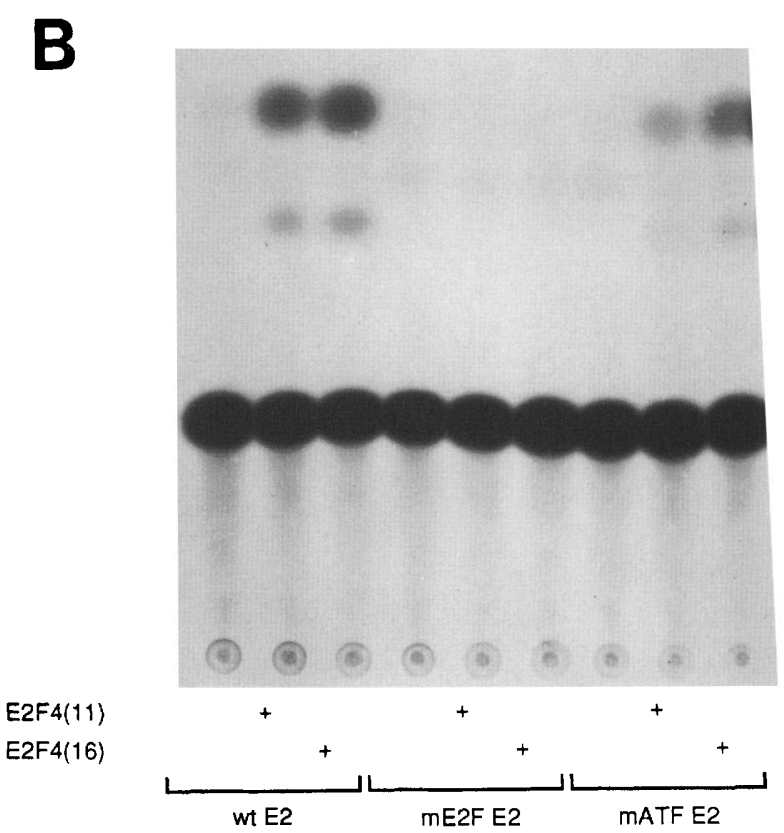

Figure 3. E2F-4 DNA binding and promoter trans-activation depend on the presence of an E2F site. (A) E2F-4 binds DNA containing an E2F site. Fifty nanograms of purified GST-E2F-4 fusion proteins were incubated with a labeled oligonucleotide corresponding to the E2F-binding site in the DHFR promoter (Shirodkar et al. 1992). A 100-fold excess of wild type (wt) or mutant (mut) competitor oligonucleotide was added, where indicated. The segments of E2F-4 cDNA used for the construction of the various GST-E2F-4 fusion proteins described here were those encoding residues 13-150 [GSTE2F4 (13-150)] or full-length E2F-4 containing either 11 [GST-E2F4(11)] or 16 [GST-E2F4(16)] serines in the polyserine region. (B) Trans-activation by E2F4. U2OS cells were transfected with $4 \mu \mathrm{g}$ of expression plasmid, pCMV-E2F$4(11)$ or pCMV-E2F-4(16), $6 \mu \mathrm{g}$ of reporter plasmid, pE2wtCAT (wtE2), pE2|-64/-60, -45/-36)CAT (mE2F E2), or pE2/-80/ -70 )CAT (mATF E2), and $2 \mu \mathrm{g}$ of pCMVBGAL. Cell extracts were prepared $40 \mathrm{hr}$ after transfection, and a CAT assay was performed on the relevant cell extracts, as described in Materials and methods. Amounts of extracts used for the CAT assay were normalized based on their $\beta$-galactosidase activity.

serines present in the polyserine region displayed similar DNA-binding activity and specificity. A deleted version of E2F-4 containing only residues $13-150$ also bound specifically to the E2F DNA, revealing that the E2F-4 DNAbinding domain is located within this region, as predicted earlier (see above).

\section{E2F-4 trans-activates the adenovirus E2 promoter}

E2F activity includes at least two components, binding to a specific DNA sequence and the ability to activate certain promoters containing this sequence. Therefore, we asked whether E2F-4 can trans-activate a promoter containing an E2F DNA-binding site(s). U2OS cells were transfected with an E2F-4 expression vector, pCMVE2F-4, and a reporter plasmid containing E2F DNA-binding sites. Three such reporters were tested. Each contained the chloramphenicol acetyltransferase (CAT) gene linked to the wild-type adenovirus E2 promoter, to an E2 promoter lacking its activating transcription factor (ATF) site $(-80 /-70)$, or to a mutant E2 promoter lacking its two E2F sites $(-64 /-60,-45 /-30$; Loeken and
Brady 1989). Cotransfection of pCMV-E2F-4 and the wild-type $\mathrm{E} 2$ promoter led to a substantial increase in the level of CAT activity. E2F-4-dependent trans-activation was also observed in the absence of the ATF site. However, the protein failed to trans-activate the E2 promoter lacking the two E2F sites (Fig. 3B). These results imply that E2F-4 can trans-activate and that this function depends on the presence of an E2F site in the responding promoter. As was the case for the DNA-binding activity, E2F-4 containing either 11 or 16 serines trans-activated equally well in these assays, and the number of serines did not affect the E2F site requirement for this function. Similar results were obtained with an E2F-4 species containing 13 serines (data not shown). Hence, within certain limits, the extent of the polyserine run had no significant effect on the measured function of this protein.

\section{E2F-4 can form heterodimers with DP-1}

Because E2F-1 functions as a heterodimer with DP-1 (Bandara et al. 1993; Helin et al. 1993; Huber et al. 1993; Krek et al. 1993), the ability of the E2F-4 protein to in- 
teract with DP-1 was assessed. U2OS cells were transfected with expression vectors encoding E2F-4, DP-1, hemagglutinin (HA)-E2F-4, and/or HA-DP-1. When extracts of the relevant cultures were employed in an E2F bandshift assay, a band (labeled A) which was present, but less intense, in untransfected cells and cells transfected with HA-DP-1, could be detected in the E2F-4 transfected cells (Fig. 4A, lane 4). Unlike the case of the other two cultures, this band in the HA-E2F-4 transfected culture was supershifted (to band B) by anti-HA antibody, 12CA5, indicating the presence of HA-E2F-4. This result again demonstrates the ability of E2F-4 to bind to an E2F site in vivo. As reported previously, cells transfected with HA-DP-1 alone displayed no additional bandshift activities (Fig. 4A, lanes 2,3), but when cells were cotransfected with E2F-4 and HA-DP-1 or HAE2F-4 and DP-1, the newly detected E2F bandshift activity (band A), described above, was considerably more intense than that detected in cells transfected with HAE2F-4 alone (Fig. 4A, cf. lanes 4, 6, and 8), and much of it was supershifted with HA antibody. When cells were cotransfected with untagged E2F-4 and DP-1, the same gel shift band was detected as in cells cotransfected with the HA-tagged versions of these proteins (Fig. 4A, cf. lanes 8 and 10|, but it could not be supershifted by the anti-HA antibody $12 \mathrm{CA} 5$, demonstrating that the antiHA antibody does not bind to either untagged proteins. Thus, under conditions in which both E2F-4 and DP-1 were overproduced, the two proteins interacted to form a prominent DNA-binding complex.

Cotransfection of E2F-4 and DP-1, together with an E2-CAT reporter plasmid, resulted in two- to threefold more CAT activity than was detected when E2F-4 was transfected alone (Fig. 4B). Similar results were obtained in different cell lines and with different promoters containing E2F DNA-binding sites (data not shown). Therefore, heterodimerization of E2F-4 and DP-1 leads to an increased trans-activation potential of E2F-4, just as was noted for E2F-1/DP-1 heterodimers (Bandara et al. 1993; Helin et al. 1993; Huber et al. 1993; Krek et al. 1993).

\section{E2F-4 interacts with p107 in vivo}

E2F bandshift activities exist in complexes containing RB, p107 and p130 (Shirodkar et al. 1992; Cobrinik et al. 1993). E2F-1, E2F-2, and E2F-3 appear to interact with RB but not with p107 in vivo (Lees et al. 1993). In an effort to determine the pocket protein-binding specificity of E2F-4, a whole-cell extract was prepared from U2OS cells transfected with HA-E2F-4. Half of the extract was immunoprecipitated with an anti-RB antibody (N9; Shirodkar et al. 1992), and the other half with an affinitypurified, polyclonal anti-p107 antibody (Shirodkar et al. 1992). Both precipitates were treated with deoxycholate (DOC) to release potentially associated proteins, and the treated supernatants were assayed for E2F DNA-binding activity. As predicted, E2F bandshift activity was detected in the supernatants derived from both the RB and p107 immunoprecipitates. Moreover, in both cases, ad-
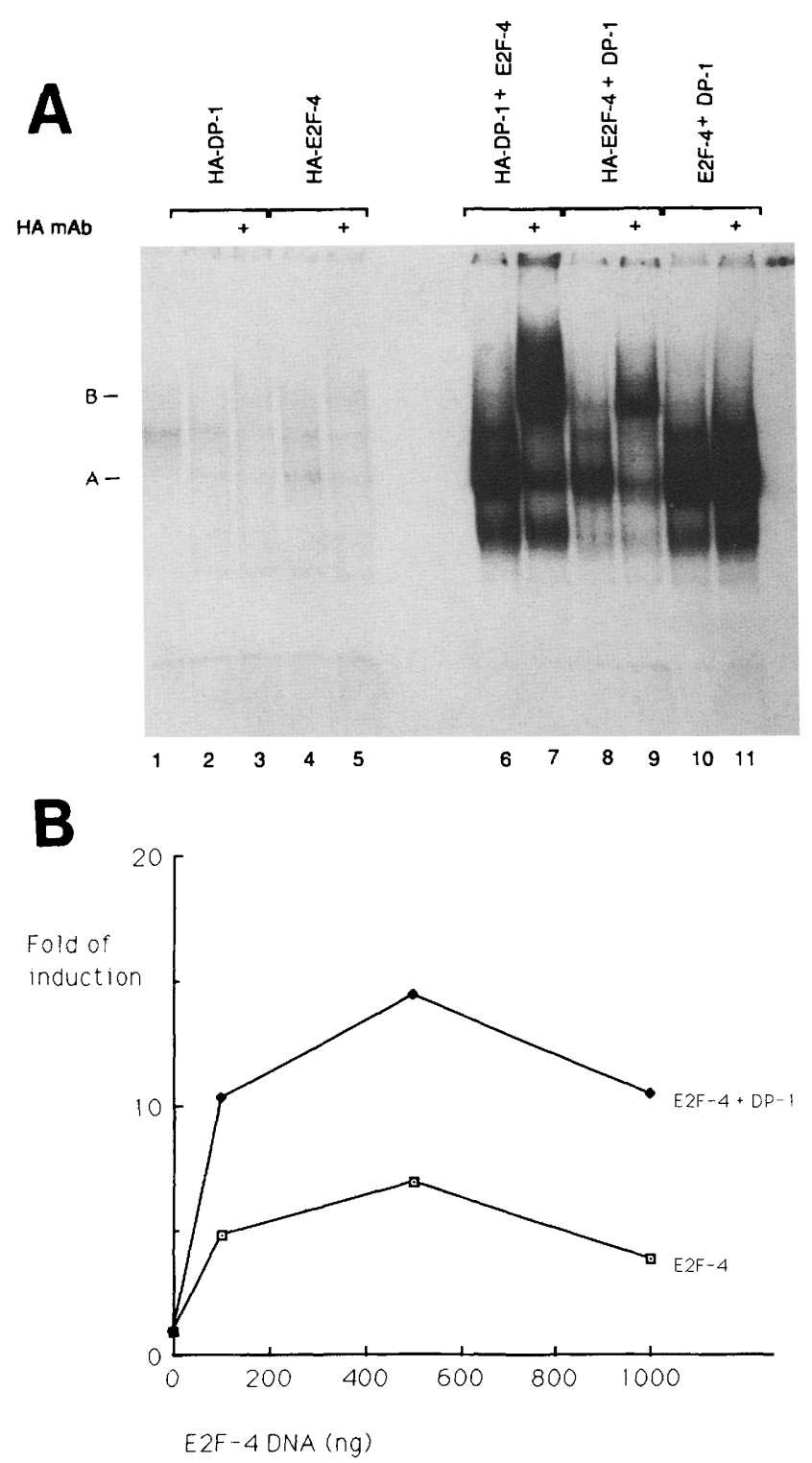

Figure 4. Coexpression of E2F-4 and DP-1 cDNAs results in increased E2F-4 DNA binding and trans-activation. $(A \mid$ E2F-4/ DP-1 heterodimerization in vivo. U2OS cells were transfected with expression plasmids (10 $\mu \mathrm{g}$ each), as indicated above each lane. (Lane 1) Untransfected cells. Cell extracts were prepared as described in Materials and methods and tested for binding to a radiolabeled oligonucleotide containing an E2F site in the presence $(+)$ or absence of the anti-HA mAb 12CA5. (B) DP-1 enhances E2F-4-dependent trans-activation. C33A cells $\left(\mathrm{RB}^{-1-}\right)$ were transfected with $5 \mu \mathrm{g}$ of pE2wtCAT, $2 \mu \mathrm{g}$ of pCMVBGAL, $200 \mathrm{ng}$ of pcDNAI-DP-1, and the indicated amounts of pCMVE2F-4. A CAT assay was performed on the resulting cell extracts. In general, $30-50 \%$ of an extract of a $10-\mathrm{cm}$ dish of cells was present in each reaction mixture. CAT values were normalized to $\beta$-galactosidase units. Results are presented as fold induction vs. quantity of E2F-4-encoding DNA transfected.

dition of anti-HA antibody to the released material supershifted a fraction of the activity (Fig. 5A). Thus, transfected E2F-4 can form a complex with both RB and p107, 

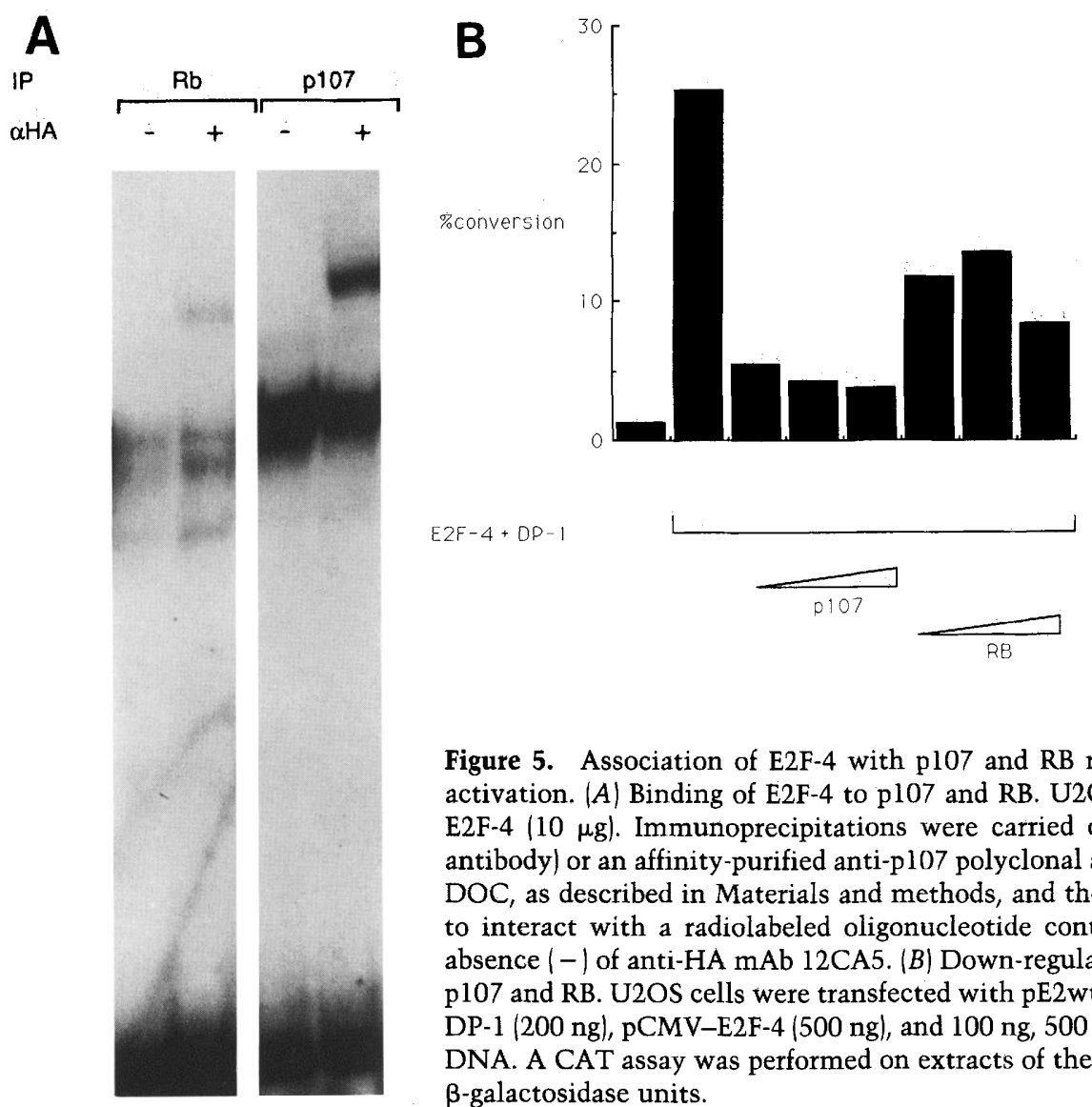

Figure 5. Association of E2F-4 with p107 and RB results in decreased E2F-4-dependent transactivation. $(A)$ Binding of E2F-4 to p107 and RB. U2OS cells were transfected with pCMV-HAE2F-4 $(10 \mu \mathrm{g})$. Immunoprecipitations were carried out with either N9 (an anti-RB polyclonal antibody) or an affinity-purified anti-p107 polyclonal antibody. The precipitates were treated with DOC, as described in Materials and methods, and the released material was tested for its ability to interact with a radiolabeled oligonucleotide containing an E2F site in the presence $(+)$ or absence (-) of anti-HA mAb 12CA5. (B) Down-regulation of E2F-4-dependent trans-activation by p107 and RB. U2OS cells were transfected with pE2wtCAT $(5 \mu \mathrm{g}), \mathrm{pCMV} \beta-\mathrm{GAL}\langle 2 \mu \mathrm{g})$, pCDNAIDP-1 (200 ng), pCMV-E2F-4 (500 ng), and $100 \mathrm{ng}, 500 \mathrm{ng}$, or $1 \mu \mathrm{g}$ of either pCMVp107 or pCMVRb DNA. A CAT assay was performed on extracts of these cultures. CAT values were normalized to $\beta$-galactosidase units.

and the E2F-4 molecules in these complexes retain DNA-binding activity.

Whereas E2F-4 can trans-activate certain promoters containing E2F sites, cotransfection of an E2F-4 and increasing quantities of a p107 expression plasmid, together with an E2-CAT reporter, led to a significant reduction in CAT activity (Fig. 5B). In the same experiment, introduction of increasing quantities of an RB expression plasmid also led to a decrease, albeit less dramatic, in E2F-4-dependent trans-activation function. Repressive effects of this type were not detected when p107 and RB mutants, which do not bind E2F, were tested (data not shown). In some experiments, cotransfection of greater quantities of $\mathrm{p} 107$ expression plasmid than the maximum amount analyzed in Figure 5B, led to less reporter action than was detected in the absence of E2F-4 cotransfection (data not shown). Therefore, in addition to negatively regulating exogenous E2F-4 trans-activation function, p107 can also suppress endogenous E2F activity, in keeping with earlier published results (Schwarz et al. 1993).

Because these experiments were performed in cells that transiently overproduce HA-E2F-4 and overproduction might, in theory, lead to unphysiologic interactions of HA-E2F-4 with one or more pocket proteins, the ability of endogenous E2F-4 to form complexes with p107 and RB was also tested. Specifically, untransfected U937
$\left(\mathrm{RB}^{+}\right)$and $\mathrm{C} 33 \mathrm{~A}\left(\mathrm{RB}^{-1-}\right)$ cells were metabolically labeled and their extracts immunoprecipitated, in parallel, with RB and p107 antibody. After washing the resulting precipitates, they were dissolved, and the solubilized proteins were reimmunoprecipitated with either E2F-4 or E2F-1 antibody. As can be seen in Figure 6A, E2F-4 was present in the p107 immunoprecipitate in both cell lines. In U937 cells, E2F-4 was also detected in the RB immunoprecipitate, although at a much reduced level compared with that detected in the p107 fraction. In the same experiment E2F-1 was present only in the RB immunoprecipitate. In $\mathrm{C} 33 \mathrm{~A}$ cells, which fail to synthesize functional $R B$, no RB/E2F-4 interaction could be detected, as expected. Taken together, these results indicate that E2F-4 interacts, under physiological conditions, with p107. It also interacts with RB, although with apparently lower affinity.

Similar to the results observed previously (Fig. 2C), the E2F-4 isolated from the anti-E2F-4 reimmunoprecipitates, migrated as a heterogeneous set of bands $\sim \sim 57-64$ $\mathrm{kD}$. Although these results do not indicate the basis for the heterogeneity, various possibilities exist to explain this phenomenon, including the existence of differentially spliced products and heterogeneously modified products of a single mRNA. Interestingly, in C33A cells, the distribution of bands isolated by direct E2F-4 immunoprecipitation and those that were isolated because 


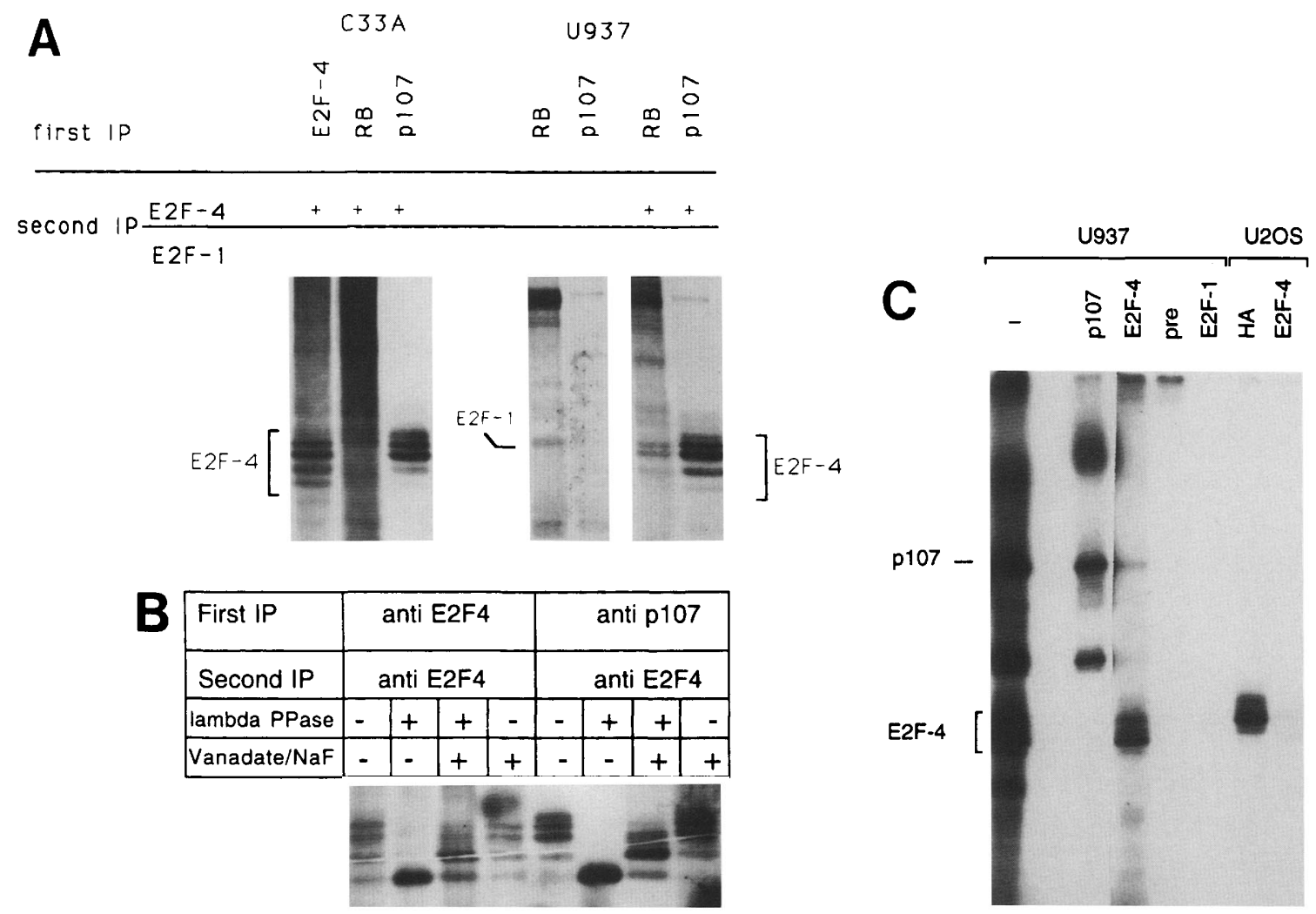

Figure 6. In vivo association of E2F-4 and p107. $(A)$ E2F-4 interacts with p107 in preference to RB in vivo. Extracts of metabolically labeled C33A and U937 cells were immunoprecipitated with a mixture of the anti-p107 mAbs SD9+SD15, the anti-RB mAb XZ77, or the anti-E2F-4 mAb GG22. The resulting precipitates were then boiled and reimmunoprecipitated by overnight incubation at $4{ }^{\circ} \mathrm{C}$, with either GG22 or, where indicated, with the anti-E2F-1 mAb SQ41. (B) E2F-4 is a phosphoprotein. Extracts of $\left[{ }^{35} \mathrm{~S}\right] \mathrm{methionine}$ metabolically labeled C33A cells were immunoprecipitated using either monoclonal antibodies against E2F-4 (GG22) or against p107 (SD9 + SD15) and reprecipitated with GG22. Immunoprecipitates were treated as indicated with $\lambda$ phosphatase with or without the phosphatase inhibitors, vanadate and $\mathrm{NaF}$, or with the inhibitors alone. $(C)$ p107-associated E2F-4 serves as a substrate for p107associated kinase(s). Extracts of U2OS cells transfected with pCMV-HA-E2F-4 (10 $\mu \mathrm{g})$ and untransfected U937 cells were immunoprecipitated with a mixture of the anti-p107 mAbs SD9 + SD15. An in vitro kinase reaction was performed on the pellets, as described in Materials and methods. Samples were boiled and reimmunoprecipitated with the same anti-p107 monoclonal mix, anti-E2F-4 rabbit polyclonal antibody, R69 (E2F-4), its preimmune serum (pre), anti-E2F-1 monoclonal (SQ41), or the anti-HA mAb 12CA5 (HA).

they were bound to p107, were not identical. This may mean that p107 selects a specific subset of the existing E2F-4 species. Alternatively, the heterogeneity may be a product of differential phosphorylation, and E2F-4 may be phosphorylated differently when bound to p107 than otherwise. To test the possibility that the heterogeneity was attributable to phosphorylation, we treated E2F-4 immunoprecipitates from metabolically labeled cells with $\lambda$ phosphatase (NEB), which catalyzes the dephosphorylation of serine, threonine, and tyrosine residues. As seen in Fig. 6B, phosphatase treatment resulted in the appearance of a single, more intense band that corresponded to the fastest migrating E2F-4 species. The effect of the phosphatase was significantly reduced in the presence of phosphatase inhibitors (Fig. 6B). These results suggest that the appearance of multiple E2F-4 bands is attributable to differential phosphorylation.

Because p107-E2F complexes are closely associated with a protein kinase activity (Faha et al. 1992; Lees et al. 1992), we asked whether E2F-4 can serve as a sub- strate for the p107-associated kinase. To this end, untransfected cell extracts were immunoprecipitated with p107 monoclonal antibody, and the precipitates were allowed to carry out an in vitro kinase reaction in the presence of radioactive $\left[\gamma^{-32}{ }^{32}\right]$ ATP. Anti-E2F-4 reimmunoprecipitation of the solubilized reaction products was then performed. The E2F-4 precipitates again contained four labeled bands of $\sim 57-64 \mathrm{kD}$, of which the three more slowly migrating bands were more intense. These bands comigrated with the E2F-4 set detected previously in the p107 precipitate (Fig. 6C). No such bands were detected when an irrelevant antibody was used in the first immunoprecipitation (data not shown). To verify that these bands are E2F-4 species, U2OS cells were transfected with HA-E2F-4 and subjected to the same analysis, except that the reprecipitation was performed with anti-HA antibody. This supernatant reprecipitate also yielded a set of four bands that were, in this case, of slightly slower mobility than those detected in untransfected cells (Fig. 6C), most probably because of the pres- 
ence of the HA tag. These results are consistent with the data presented above, suggesting that all of the antiE2F-4 reimmunoprecipitated bands isolated from the untransfected U937 cell extract were E2F-4 species differing from one another in their state of phosphorylation. Furthermore, these results suggest that E2F-4 can serve as a substrate for the p107-associated kinase, in keeping with the speculation noted above. Although the experiments described in Figure 6C were performed with an E2F-4 polyclonal antibody, identical results were obtained with monoclonal E2F-4 antibody, GG22 (data not shown).

\section{E2F-4 has transforming activity that can be suppressed by binding of a pocket protein}

We next examined whether E2F-4 has transforming activity. We decided to analyze, in addition to wild-type E2F-4, an E2F-4 mutant that was refractory to p107 suppression of its trans-activation function. To this end, 4 residues $(407-411)$ of the 18-amino-acid pocket proteinbinding unit of E2F-4 were deleted. The resulting mutant (E2F-4dl4) could still trans-activate but was significantly less repressible by p107 than wild-type E2F-4 (Fig. 7A). Recombinant retroviruses encoding wild-type E2F-4 and E2F-4dl4 were used to infect NIH-3T3 cells. Stable infectants were selected as pools of neomycin-resistant cells that were then analyzed for anchorage-independent growth using a soft agar growth assay. As shown in Figure 7B, E2F-4dl4-infected cultures regularly formed colonies in soft agar, whereas E2F-4-infected cultures did not. Furthermore, the E2F-4dl4-infected cells formed large tumors in nude mice after 2 weeks, whereas at the same time, an identical number of the wild-type E2F-4infected cells had generated a barely detectable nodule at the site of injection (data not shown). These data imply that, like E2F-1, E2F-2, and E2F-3, E2F-4, also, has transforming activity (G. Xu, D.M. Livingston, and W. Krek, in prep.). They further imply that this activity is normally down-modulated or suppressed by pocket protein binding.

\section{E2F-4 chromosomal localization}

The chromosomal location of the E2F-4 gene was determined using fluorescent in situ hybridization with a 15$\mathrm{kb}$ E2F-4 genomic probe. The genomic clone was initially isolated using a fragment of the E2F-4 cDNA to probe a human placenta genomic library (Clontech). A partial sequence of this clone was determined to confirm that it was a segment of the E2F-4 gene (data not shown). Hybridization of this probe to human metaphase chromosomes is illustrated in Figure 8A, and an idiogram summarizing the data for 20 cells is presented in Figure 8B. A signal was consistently observed on both sister chromatids of the long arm of chromosome 16. Analysis of DAPI-banded chromosomes revealed that most signals localized to $16 \mathrm{q} 22$, or, in a few cases, to the interface of $16 \mathrm{q} 21$ and $\mathrm{q} 22$. Chromosome staining was reversed from color to black and white, to increase contrast and to

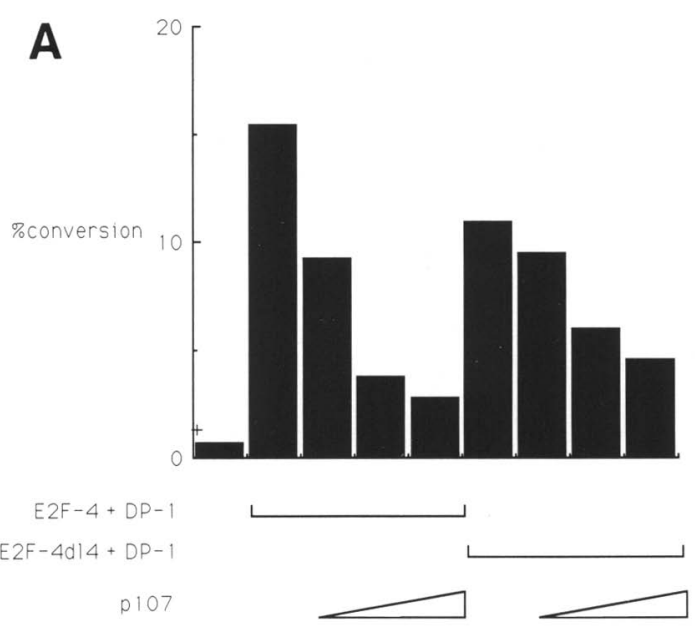

B

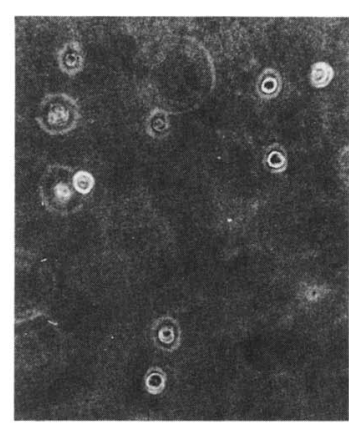

$E 2 F-4$

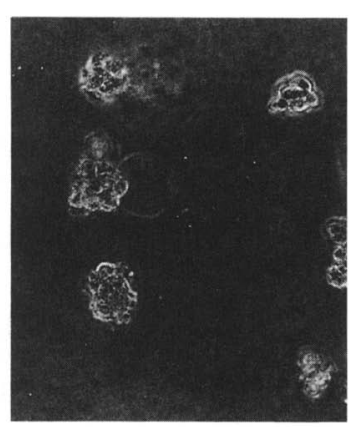

$E 2 F-4 d 14$
Figure 7. An E2F-4 derivative confers growth in soft agar. (A) E2F-4d14 is less responsive to p107 repression than wild-type E2F-4. U2OS cells were transfected with $5 \mu \mathrm{g}$ of E2-CAT, $2 \mu \mathrm{g}$ of pCMVBGAL, $200 \mathrm{ng}$ of pcDNAI-DP-1, $500 \mathrm{ng}$ of either pCMV-E2F-4 or pCMV-E2F-4d14, and 10,50, or $100 \mathrm{ng}$ of $\mathrm{pC}$ MVp107. The resulting cell extracts were analyzed by CAT as say. CAT values were normalized to $\beta$-galactosidase units. $(B)$ Soft-agar growth of NIH-3T3 cells producing E2F-4 and E2F4d14. NIH-3T3 cells were infected with recombinant retroviruses encoding either wild-type or dl4 mutant E2F-4. Resulting infected cell populations, isolated as G418-resistant cell pools, were isolated and characterized as described in Materials and methods. Cell pools were assayed in soft agar growth assays (G. $\mathrm{Xu}, \mathrm{D} . \mathrm{M}$. Livingston, and W. Krek, in prep.) and photographed after 14 days.

display DAPI bright bands as dark G bands. In the vast majority of chromosome spreads, this site on chromosome 16 was clearly the only site specifically labeled. This is consistent with there being a single copy of the E2F-4 gene in the human genome, mapping to16q22.

\section{Discussion}

A new member of the E2F family, E2F-4, was cloned and found to have structural and functional properties that both liken it to existing members of the family and reveal its unique nature. Like the previously described $\mathrm{E} 2 \mathrm{~F}$ species, E2F-4 has traditional E2F DNA sequence recognition properties, and its amino acid sequence includes a 
Figure 8. E2F-4 chromosomal location. $(A)$ Localization of the E2F-4 gene to human chromosome $16 \mathrm{q} 22$ by fluorescent in situ hybridization. DAPI-banded chromosomes were reversed to display DAPI bright bands as dark $\mathrm{G}$ bands, with hybridization signals visualized as white spots (arrowheads) present on both chromatids. (B) Idiogram of chromosome 16 depicting the distribution of hybridization signals from the $15-\mathrm{kb}$ genomic E2F-4 phage clone following in situ hybridization analysis of 20 representative metaphases. Each bar denotes the placement of signal on an individual chromosome and is intended to convey the range of precision with which that signal could be placed. The most likely consensus from this analysis placed the gene in the upper region of 16q22, corresponding to $16 \mathrm{q} 22.1$, with some signals localized to the interface of bands 16q21 and 16q22.1.
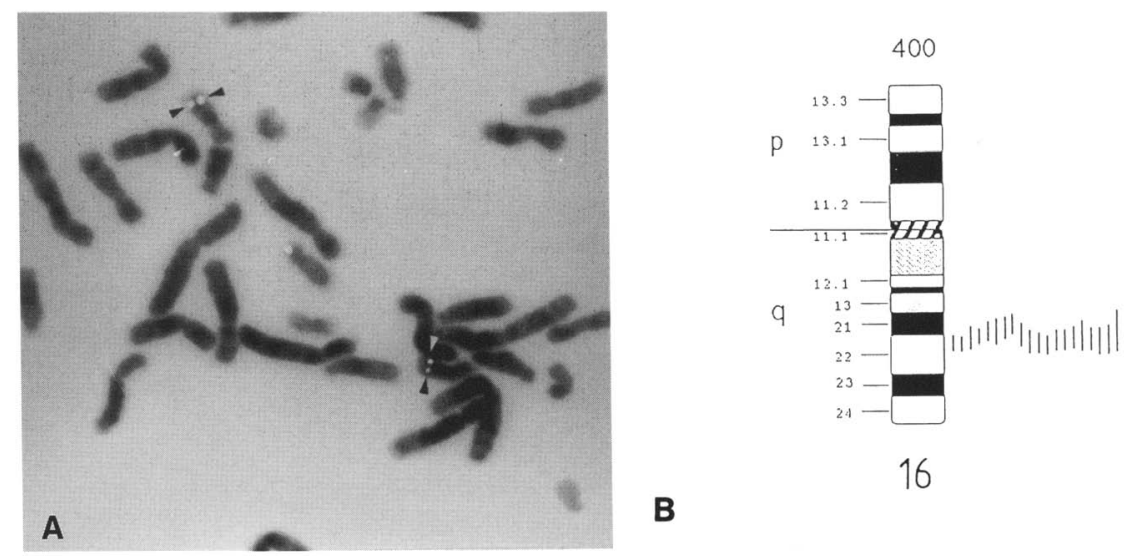

B discrete DNA-binding domain in its amino-terminal half. It also carries a potent carboxy-terminal acidic trans-activating unit, within which is embedded a pocket protein-binding motif. Like the other three known E2F species, it too forms heterodimeric complexes with a member of the DP family, and complex formation enhances its DNA-binding and transactivating functions. Whether heterodimer formation depends on the integrity of its putative zipper-like structure, as is the case for E2F-1 (Krek et al. 1994), remains to be determined.

With regard to its primary structure, its DNA-binding domain, zipper-like structure, carboxy-terminal acidic trans-activator, and pocket protein-binding motif are also family signatures. Yet, in vivo, E2F-4 interacts only weakly with RB, unlike E2F-1, E2F-2, and E2F-3 (Helin et al. 1992; Kaelin et al. 1992; Ivey-Hoyle et al. 1993; Lees et al. 1993). This implies that its pocket protein-binding motif, while significantly homologous to that of the other E2F species, may have subtle features that direct it to p107. Alternatively, other structural characteristics of E2F-4 may, along with the pocket protein-binding sequence, contribute to the unique pocket-binding specificity of this protein. Furthermore, E2F-4 lacks an aminoterminal cyclin-binding motif along with a basic region, which the three other E2F species have. Because cyclin A binding to E2F-1, the best understood case, is linked to the negative regulation of its transcriptional activation function in $S$ and $G_{2}$ (Krek et al. 1994), it is possible that E2F-4 is not subject to this form of periodic control of its core function. This would be consistent with the fact that E2F-4 gene expression and the prevalence of E2F-4 protein are reasonably constant through the cell cycle, unlike the expression of the E2F-1 gene, which is late $G_{1}$ and S phase specific (Kaelin et al. 1992; Krek et al. 1994). Among other possibilities, it may be that E2F-4 function is evenly manifest through the cycle, and if so, some of its target genes might include those whose functions are continuously needed during more than one phase of the cycle for smooth growth progression and/or for passage through serial cell cycles. Alternatively, E2F-4 might be subject to regulation by cyclin A-kinase, not by direct cyclin A-kinase binding, as is the case with E2F-1 (Krek et al. 1994), but via p107 that interacts independently with both E2F-4 and cyclin A. The observation that E2F-4 is overtly phosphorylated and serves as a substrate for the p107-associated kinase supports this possibility. However, if such cell-cycle phosphorylations occur, they do not result in overt mobility shifts of E2F-4.

The oligoserine array of E2F-4 is also a unique characteristic of the protein. Thus far, we have been unable to link its existence to an aspect of E2F-4 function or regulation of function. Furthermore, in a brief search, there was no evidence of oligoserine amplification in a limited number of human colon tumors marked by CA repeat amplification. This does not eliminate the possibility that such an association exists and, if so, that amplification of the number of serines in the E2F-4 array, in some way, contributes to the evolution of a neoplastic phenotype in certain human tumors. More screening will be needed before such an association can be established or ruled out.

That E2F-4 may be the product of a proto-oncogene is supported by the observation that a derivative can transform at least one line of rodent cells. The existence of this activity is consistent with the recent observation that the other three members of the family are also capable of inducing anchorage-independent growth and monolayer overgrowth of untransformed immortalized cell lines (G. Xu, D.M. Livingston, and W. Krek, in prep.). What is more revealing is the fact that the wild-type protein lacked overt transforming activity in the assay employed, whereas a mutant derivative, less responsive to repression by its pocket protein-binding partner(s), for example, pl07, was clearly active in this regard. These data strongly suggest that pocket protein binding to E2F-4 can suppress its transforming function. Better still, because pocket protein binding also led to marked inhi- 
bition of E2F-4 trans-activating function, it may be that transformation by E2F-4 is, at least in part, a property of its transcriptional activation function. If this is so, transformation suppression by 107 and/or another pocket protein partner, for example, p130, might, in part, be a product of its ability to suppress E2F-4 trans-activating function.

It should also be noted that the NIH-3T3 cells used in these transformation assays produce abundant p107. Conceivably, other immortal, but otherwise untransformed cell lines contain lower levels of this E2F-4 regulator. In such cells, it would not be surprising to find that wild-type E2F-4 displays transforming activity, which may, in this case, arise because of a relative deficiency in p107.

Heretofore, little has been discovered that speaks to a unique aspect of $\mathrm{p} 107$ function. There is evidence that unique features exist: the distinct timing of its interaction with E2F (Shirodkar et al. 1992), its cell cycle-dependent synthesis (Cobrinik et al. 1993), and differences in the mechanism by which it induces $\mathrm{G}_{1}$ arrest in $\mathrm{RB}^{-1-}$ cells (Zhu et al. 1993). Results presented here reveal a clear biochemical difference between its function and that of RB. That it normally interacts with E2F-4 much more efficiently than RB suggests that $R B$ and p107 transmit different transcriptional signals, perhaps to different genes, via analogous molecular pathways. When a series of E2F-driven promoters were cotransfected with E2F-1 and E2F-4, in parallel, there were significant, albeit not absolute, differences in the responses of some of them to these two related transcription factors (D. Ginsberg and D.M. Livingston, unpubl.). Results of this kind are consistent with the notion that both the transcription factors, themselves, and the pocket proteins that regulate them operate on different genes by analogous, but not identical, biochemical pathways. This notwithstanding, it should also be noted that the transcription assays employed to date are not completely incisive, and the repertoire of E2F-dependent promoters is limited. Therefore, it remains possible that there are certain promoters in which E2F-4 and another E2F family member both have an important role to play, along with their pocket protein partners. If so, there may be subtle timing and/or tissue-specific expression functions, not heretofore apparent, that are the responsibility of these regulator/factor complexes.

\section{Materials and methods}

Cell culture and synchronization

Unless otherwise stated, all cells were grown at $37^{\circ} \mathrm{C}$ in a $10 \%$ $\mathrm{CO}_{2}$-containing atmosphere. HeLa, 293, C33A, U2OS, and the retroviral packaging cell line, $\Psi 2$, were maintained in Dulbecco's modified Eagle medium (DMEM) supplemented with $10 \%$ fetal calf serum (FCS, Hyclone). NIH-3T3 cells were maintained in DMEM supplemented with $5 \%$ bovine calf serum (BCS, Hyclone). U937 cells were grown at $5 \% \mathrm{CO}_{2}$ in (RPMI) supplemented with $10 \%$ FCS. NIH-3T3 cells were growth arrested by incubating cells for $65 \mathrm{hr}$ in DMEM containing $0.5 \% \mathrm{BCS}$. Cells were stimulated by addition of BCS to a final concentration of $20 \%$ and harvested at appropriate times thereafter.

\section{Plasmids}

GST-E2F-4(11) and GST-E2F-4(16) were constructed by onestep PCR using oligonucleotides 636 and 637 (see below) and then subcloning in GST-TK. GST-E2F-4(13-150) was constructed by one-step PCR using oligonucleotides 610 and 560 (see below) and then subcloning in GST-TK. Mammalian expression vectors pCMV-E2F-4(11) and pCMV-E2F-4(16) were generated by replacing the wild-type E2F-1 CDNA in pcDNAI(E2F-1) (Krek et al. 1993) with the 1.2-kb BamHI-EcoRI fragment from the respective recombinant GST-E2F-4 plasmids. Similarly, mammalian expression vectors, pCMV-E2F4(13) and pCMV-E2F-4d14, were constructed by one-step PCR using oligonucleotides 636,637 , and 636,936 , respectively. The sequences of PCR products were verified by DNA sequencing. HA-tagged E2F-4 and E2F-4dl4 expression vectors were generated by replacing the wild-type E2F-1 cDNA in pcDNAI/HAE2F-1) (Krek et al. 1993) with the 1.2-kB BamHI-EcoRI fragment from the respective pCMV-E2F-4 plasmids. Sequences of the primers were as follows: 636; 5'-GGTGGATCCGCGATGGCGGAGGCCGGG-3', 637; 5'-GGGGAATTCTCAGAGGTTGAGAACAGG-3', 610; 5'-GGTGGATCCACCATGGGCACTCCAAGCCGGCACGAA-3', 560; 5'-GGGGAATTCTCAAGCAAAGCATCTGCAG-3', 936; and 5'-GGGGAATTCTCAGAGGTTGAGAACAGGCACACAGACACCTTCACTCTC-3'. Retroviral vectors carrying E2F-4 and E2F-4dl4 were generated by cloning cDNA fragments encoding HA-tagged E2F-4 and E2F-4dl4 into the retroviral vector pCMV-neo (Bengal et al. 1992). These cDNA fragments were generated by digesting the corresponding pCMV-HA-E2F-4 plasmids with HindIII-EcoRI. The resulting fragments were isolated, treated with Klenow polymerase to generate blunt ends, and ligated into the HpaI site of pCMV-neo.

Other plasmids used here have been described previously: pCMV-Rb (Qin et al. 1992), pCMVp107 (Zhu et al. 1993), pcDNAI-DP-1 and pcDNAI-HA-DP-1 (Krek et al. 1993), pE2wtCAT (wtE2), pE2(-64/-60, -45/-36)CAT and pE2(-80/-70)CAT (Helin et al. 1992).

\section{Isolation of E2F-4 cDNA}

RNA from human $T$ cells was prepared as described previously (Chomczynski et al. 1987). Selection for poly(A) ${ }^{+}$mRNA was performed using a Pharmacia mRNA purification kit according to the manufacturer's instructions. This poly $(\mathrm{A})^{+}$mRNA was subjected to a reverse transcription reaction and PCR using the oligonucleotides 5'-GGTGCAGAAGCGGCGCATCTATGAC$3^{\prime}$ and 5'-CGCGGATCCATGGAAATCCAGGGGGGTGAGGTCCCCA-3'. Following subcloning into BlueScript and partial sequencing, the PCR product corresponding to E2F-4 was used to screen Nalm6 Zap cDNA library (a gift of A. Bernards, Massachusetts General Hospital, Charlestown) and HeLa $\lambda$ Zap cDNA library (Xiao et al. 1991) according to standard procedures (Ausubel et al. 1987).

\section{Sequencing}

The E2F-4 cDNA sequence was established by sequencing overlapping cDNA inserts using the dideoxy-chain termination method with the Sequenase kit 2.0 (U.S. Biochemical Corp.). Verification of sequences of PCR products was performed using an Applied Biosystems automated sequencer.

\section{Analysis of the CAG repeat region}

Extracts containing genomic DNA was prepared from $2 \times 10^{6}$ cells or $50 \mu$ l of whole blood by washing cells three times in TE 
buffer and then incubating them for $1 \mathrm{hr}$ at $56^{\circ} \mathrm{C}$ in $100 \mathrm{ml}$ of $\mathrm{K}$ buffer $\left(50 \mathrm{~mm} \mathrm{KCl}, 10 \mathrm{mM}\right.$ Tris- $\mathrm{HCl}, 2.5 \mathrm{~mm} \mathrm{MgCl}_{2}, 0.5 \%$ Tween $-20,100 \mathrm{mg} / \mathrm{ml}$ of proteinase $\mathrm{K})$. Following heating for 15 min at $90^{\circ} \mathrm{C}, 5 \mu \mathrm{l}$ was used for a PCR with the oligonucleotides 5 ' - CGGGATCCTGGACACCCGGCCACTGCAGTCTTCTGCC-3' and 5'-CGGAATTCCTCAAAGGAGGTAGAAGGGTTGGGTCCG-3' corresponding to nucleotides 879-909 and 990-1017 in E2F-4, respectively. Prior to PCR, one of the oligonucleotides was end-labeled using T4 kinase and $\left[\gamma^{-32} \mathrm{P}\right] \mathrm{ATP}$. PCR products were resolved in a sequencing gel.

\section{FACS analysis}

Flow cytometry analysis was performed as described previously (Ewen et al. 1993).

\section{Northern blot analysis}

Total RNA was isolated from cells cultured in 15-cm dishes essentially as described previously (Chomczynski et al. 1987). This material was enriched for poly(A) RNA by one round of chromatography on oligo(dT)-cellulose (Pharmacia, mRNA purification kit) according to the manufacturer's instructions. RNA, resolved by electrophoresis in a $1.1 \%$ formaldehyde$1.0 \%$ agarose gel, was transferred to Hybond $\mathrm{N}$ (Amersham) according to the manufacturer's instructions and hybridized to cDNA probes radiolabeled by random priming (Boehringer Mannheim, random-primed DNA labeling kit) as instructed by the manufacturer. For high stringency conditions, filters were prehybridized for at least $4 \mathrm{hr}$ at $42^{\circ} \mathrm{C}$ with $50 \%$ formamide, $5 \times$ SSC, $5 \times$ Denhardt's solution, $50 \mu \mathrm{g} / \mathrm{ml}$ of denatured salmon sperm DNA, and $25 \mathrm{mM} \mathrm{KPO}_{4}(\mathrm{pH} \mathrm{7.4)}$ and then hybridized to labeled probe at $42^{\circ} \mathrm{C}$ overnight in the same solution containing $10 \%$ dextran sulfate. Filters were rinsed briefly in $2 \times$ SSC followed by $4 \times 20-\mathrm{min}$ washes; two washes in $2 \times$ SSC, $0.1 \%$ SDS at room temperature, then a wash in $1 \times \mathrm{SSC}, 0.1 \%$ SDS at $55^{\circ} \mathrm{C}$, and finally a wash in $0.2 \times \mathrm{SSC}, 0.1 \%$ SDS at $55^{\circ} \mathrm{C}$. Low stringency conditions, used for cross-species reactions, were similar except that for prehybridization and hybridization, the formamide content was reduced to $20 \%$ and the final two washes were once at $35^{\circ} \mathrm{C}$ in $2 \times \mathrm{SSC}, 0.1 \%$ SDS and once in $1 \times \mathrm{SSC}, 0.1 \%$ SDS. Autoradiography was performed at $-70^{\circ} \mathrm{C}$ with intensifying screens. Consecutive hybridizations were performed on filters that had been stripped by boiling in $0.1 \%$ SDS for $20-40$ min. Efficient removal of labeled probe was checked by autoradiography prior to reprobing.

\section{cDNA probes}

The following DNA probes were used in the hybridization reactions noted in this report: Human E2F-4, a 200-bp SmaI-SfiI fragment (nucleotides 271-472) of the human cDNA; murine E2F-1, a 1.7-kb partial cDNA corresponding to murine E2F-1 (Li et al. 1994); murine DP-1, a 2.2-kb EcoRI-Xhol fragment of the murine cDNA (Girling et al. 1993); 36B4, a 0.8-kb PstI fragment of human 36B4 acidic ribosomal phosphoprotein PO (Laborda 1991).

\section{Immunoblotting}

Samples of whole-cell extracts, prepared as described previously (Shirodkar et al. 1992), were subjected to electrophoresis (200 $\mu \mathrm{g}$ of cellular protein per lane) in $8 \%$ SDS-polyacrylamide gels. After transfer to Hybond-C extra (Amersham), the membranes were blocked for 4-6 hr with $5 \%$ nonfat milk in Tris-buffered saline at $\mathrm{pH} 8.0$ (TBS), washed, and incubated overnight at $4^{\circ} \mathrm{C}$ with a 1:10 dilution of anti-E2F-4 mAb GG22 hybridoma tissue culture supernatant in TBS plus $3 \%$ BSA. Immune complexes were detected as described previously (Ludlow et al. 1989) with alkaline phosphatase-conjugated rabbit anti-mouse secondary antibody (Boehringer-Manheim).

\section{Bandshift assay}

The expression of GST fusion proteins in Escherichia coli, their purification on glutathione-Sepharose, and their elution were as described previously (Kaelin et al. 1991). The procedure for the preparation of whole-cell extracts has been described /Krek et al. 1993). E2F DNA-binding assays using an oligonucleotide containing an E2F site derived from the DHFR promoter and release of proteins from immune complexes by DOC treatment followed by E2F bandshift assay were carried out essentially as described (Shirodkar et al. 1992). For antibody perturbation experiments, $1 \mu \mathrm{l}$ of mAb $12 \mathrm{CA} 5$ was added to the reaction mix. Approximately $50 \mathrm{ng}$ of GST fusion proteins were added to the DNA-binding reaction, where indicated.

\section{Transient transfections}

Cells were transfected by a modified calcium-phosphate protocol (Qin et al. 1992) with $10 \mu \mathrm{g}$ of plasmid DNA per 10-cm dish. Cells were harvested $40 \mathrm{hr}$ after transfection and lysed by freeze-thaw in $100 \mu \mathrm{l}$ of $250 \mathrm{~mm}$ Tris- $\mathrm{HCl}$ (pH 8.0). Extracts were assayed for $\beta$-galactosidase and CAT activities by standard procedures (Gorman et al. 1982; Shirodkar et al. 1992).

\section{Production of antibodies}

Polyclonal antibody against gel-purified full-length GST-E2F-4 fusion protein was raised in New Zealand white rabbits by standard techniques (Harlow and Lane 1988). To generate monoclonal antibody, a full-length GST-E2F-4 fusion protein was injected intraperitoneally into BALB/c mice. Spleen cells of positive animals were fused to NS-I cells according to standard procedures (Harlow and Lane 1988). Supernatants from the resulting hybridomas colonies were screened for their ability to immunoprecipitate ${ }^{35} \mathrm{~S}$-labeled, in vitro-translated full-length E2F-4.

\section{Cell labeling and immunoprecipitation}

Cells were labeled for $4 \mathrm{hr}$ using $2-3 \mathrm{mCi}$ of $\left[{ }^{35} \mathrm{~S}\right]$ methionine per $10-\mathrm{cm}$ dish of adherent cells, or $1 \mathrm{mCi} / \mathrm{ml}$ containing $10^{7}$ cells for suspension cells, in DMEM containing 10\% dialyzed FCS. Cells were lysed for $20 \mathrm{~min}$ on ice in $1 \mathrm{ml}$ of TNN buffer $150 \mathrm{mM}$ Tris- $\mathrm{HCl}$ at pH 7.4, $120 \mathrm{~mm} \mathrm{NaCl}, 5 \mathrm{~mm}$ EDTA, 0.5\% NP-40, 50 $\mathrm{mM} \mathrm{NaF}, 0.2 \mathrm{mM}$ sodium orthovanadate, $1 \mathrm{~mm}$ DTT, $1 \mathrm{~mm}$ PMSF, and $20 \mu \mathrm{g} / \mathrm{ml}$ of aprotinin). The lysate was then centrifuged for $10 \mathrm{~min}$ at $10,000 \mathrm{~g}$. Following preclearing for $30 \mathrm{~min}$ with $60 \mu \mathrm{l}$ of $50 \%$ (vol/vol) suspension of protein A-Sepharose (Pharmacia), supernatants were incubated on a rocker for $1 \mathrm{hr}$ with $100 \mu \mathrm{l}$ of the indicated antibodies (for mouse monoclonal antibodies the immunoprecipitation was treated with rabbit anti-mouse IgG antibody (Cappel) for $30 \mathrm{~min}$ ). Fifty microliters of protein A-Sepharose was then added, and incubation was continued for $30 \mathrm{~min}$. Immune complexes were collected by centrifugation and washed four times with TNN buffer. For reprecipitations, washed immunobeads were boiled for $10 \mathrm{~min}$ in $100 \mu \mathrm{l}$ of $50 \mathrm{mM}$ Tris $-\mathrm{HCl}(\mathrm{pH} 7.5), 1 \% \mathrm{SDS}$, and $5 \mathrm{mM} \mathrm{DTT}$, followed by addition of $1.3 \mathrm{ml}$ of TNN buffer. Subsequently, samples were incubated with $100 \mu$ l of indicated antibodies overnight at $4^{\circ}$, and immune complexes were collected and 
treated as described above. Samples were resuspended in SDS sample buffer, boiled, separated by SDS-PAGE, and detected by autoradiography.

\section{Phosphatase treatment}

Immunoprecipitates prepared as described above were washed once and resuspended in $60 \mu \mathrm{l}$ of phosphatase buffer, and 500 units of $\lambda$ phosphatase (NEB) was added to the appropriate tubes and incubated at $30^{\circ} \mathrm{C}$ for $1 \mathrm{hr}$. Where indicated, the phosphatase inhibitors vanadate $(10 \mathrm{mM})$ and $\mathrm{NaF}(5 \mathrm{mM})$ were included as controls.

\section{In vitro kinase assay}

After immunoprecipitation and washing, the beads were washed once with kinase buffer (50 mM HEPES at pH 7.0, $10 \mathrm{mM}$ $\mathrm{MgCl}_{2}, 5 \mathrm{mM} \mathrm{MnCl}_{2}, 1 \mathrm{mM} \mathrm{DTT}$ ) and incubated with $30 \mu \mathrm{l}$ of kinase buffer containing $10 \mu \mathrm{Ci}\left[\gamma^{-32} \mathrm{P}\right] \mathrm{ATP}$ (NEN) for $20 \mathrm{~min}$ at $37^{\circ} \mathrm{C}$. The reaction was terminated by addition of $30 \mu \mathrm{l}$ of Laemmli buffer, boiled, diluted, reimmunoprecipitated for $1-2 \mathrm{hr}$ as described above and loaded on a gel.

\section{Genomic DNA cloning}

A human placental genomic library (Clontech Laboratories Inc.) was screened with ${ }^{32}$ P-labeled E2F-4 cDNA by a standard procedure to isolate human E2F-4 genomic DNA fragments. The E2F-4 probe was a product of PCR, using oligonucleotides $5^{\prime}$ GGGATGGGCACCTCCAGG-3' and 5'-CGTGGCGGCGGCGCGCC-3', which correspond, respectively, to nucleotides 492-509 and -54 to -38 of E2F-4, as primers and E2F-4 cDNA as template.

\section{Gene localization by in situ hybridization}

The fluorescence hybridization procedure for detection of single-locus sequences was used as described previously (Lawrence et al. 1990; Johnson et al. 1991). A 15-kb genomic probe for the E2F-4 gene was labeled by nick translation with digoxygenindUTP and detected with rhodamine-conjugated anti-digoxygenin. Hybridization was done overnight at $37^{\circ} \mathrm{C}$ in $50 \%$ formamide, $2 \times$ SSC to cytogenetic preparations of normal peripheral blood lymphocytes. Metaphase chromosomes were banded for identification by immersion in DAPI. The red fluorescent signal was captured in precise registration with the blue DAPI bands using a triple-band pass filter (Chroma Inc.) and a filter wheel. Twenty metaphase figures were analyzed by two individuals. To facilitate the analysis, images were displayed in black and white to increase contrast, such that the DAPI bands appear as dark "G-bands", and the hybridization signals appear as white spots.

\section{Retrovirus packaging, retroviral infection, and soft} agar assays

$\Psi 2$ cells were transfected with the relevant plasmid using $\mathrm{Li}$ pofectAMINE reagent (GIBCO BRL) as described (G. Xu, D.M. Livingston, and W. Krek, in prep.). For infection of NIH-3T3 cells, $3 \mathrm{ml}$ of retroviral supernatant, supplemented with $8 \mathrm{mg} /$ $\mathrm{ml}$ of polybrene (Sigma), was added to exponentially growing cells and incubated for $4 \mathrm{hr}$ at $37^{\circ} \mathrm{C}$. Then, $7 \mathrm{ml}$ of DMEM, containing $5 \%$ BCS was added, and incubation was continued for $24 \mathrm{hr}$. Subsequently, the medium was changed and replaced with selection medium containing $400 \mathrm{mg} / \mathrm{ml}$ of neomycin (Sigma). After 10 days of selection, colonies from each plate were pooled and used for soft agar assay. Both for E2F-4 and E2F4d14, two independent pools of virus-infected cells were obtained and used in this assay. Soft agar assays were carried out as described (G. Xu, D.M. Livingston, and W. Krek, in prep.). Cells in soft agar were photographed after incubation for 14 days.

\section{Acknowledgments}

We are grateful to all of our divisional colleagues for helpful discussions. We are particularly grateful to Dr. R. Bernards for sharing his results on the cloning and characterization of E2F-4 with us prior to publication. We thank Dr. W. Krek for plasmids, pCDNAI-DP-1 and pCDNAI-HA-DP-1; Dr. N. Dyson for antibodies XZ77, SD9, and SD15; Dr. Liang Zhu for plasmid pCMVp107; Dr. I. Verma for plasmid pCMV-neo; Dr. W.R. Sellers for Akata cell mRNA and help with the analysis of blood samples; Drs. R. Kolodner and J.D. Griffin for tumor samples; and Jianmin Gan for technical assistance with monoclonal antibody production. D.G. was supported by a postdoctoral fellowship from the Damon Runyon-Walter Winchell Cancer Research Fund (DRG-1202). G.V. is a recipient of a National Health and Medical Research Council of Australia, C.J. Martin postdoctoral fellowship. T.C. was supported by a postdoctoral fellowship from the National Institutes of Health (NIH). Z.X. was supported by a postdoctoral fellowship from the Anna Fuller fund. G.X. was supported by a Sandoz Drug Discovery Program Fellowship. This work was supported by grants from NIH and from the Sandoz Drug Discovery Program.

The publication costs of this article were defrayed in part by payment of page charges. This article must therefore be hereby marked "advertisement" in accordance with 18 USC section 1734 solely to indicate this fact.

\section{References}

Ausubel, F.M., R. Brent, R.E. Kingston, D.D. Moore, J.G. Seidman, J.A. Smith, and K. Struhl. 1987. Current protocols in molecular biology. John Wiley/Greene, New York.

Bagchi, S., R. Weinmann, and P. Raychaudhuri. 1991. The retinoblastoma protein copurifies with E2F-I, an E1A-regulated inhibitor of the transcription factor E2F. Cell 65: 1063-1072.

Bandara, L.R., V.M. Buck, M. Zamanian, L.H. Johnston, and N.B. La Thangue. 1993. Functional synergy between DP-1 and E2F-1 in the cell cycle regulating transcription factor DRTF1/E2F. EMBO J. 12: 4317-4324.

Bengal, E., L. Ransone, R. Scharfmann, V.J. Dwarki, S.J. Tapscott, H. Weintraub, and I.M. Verma. 1992. Functional antagonism between $\mathrm{c}$-jun and MyoD proteins: A direct physical association. Cell 68: 507-519.

Blake, M. and J.C. Azizkhan. 1989. Transcription factor E2F is required for efficient expression of the hamster dihydrofolate reductase gene in vitro and in vivo. Mol. Cell. Biol. 9: 49945002.

Cao, L., B. Faha, M. Dembski, L.-H. Tsai, E. Harlow, and N. Dyson. 1992. Independent binding of the retinoblastoma protein and p107 to the transcription factor E2F. Nature 355: 176-179.

Chellappan, S.P., S. Hiebert, M. Mudryi, J.M. Horowitz, and J.R. Nevins. 1991. The E2F transcription factor is a cellular target for the RB protein. Cell 65: 1053-1061.

Chittenden, T., D.M. Livingston, and W.G.J. Kaelin. 1991. The T/ElA-binding domain of the retinoblastoma product can interact selectively with a sequence-specific DNA-binding protein. Cell 65: 1073-1082. 
Chittenden, T., D.M. Livingston, and J.A. DeCaprio. 1993. Cell cycle analysis of E2F in primary human $T$ cells reveals novel E2F complexes and biochemically distinct forms of "free" E2F. Mol. Cell. Biol. 13: 3975-3983.

Chomczynski, P. and N. Sacchi. 1987. Single step method of RNA isolation by acid guanidinium thiocyanate-phenolchloroform extraction. Anal. Biochem. 162: 156-159.

Cobrinik, D., P. Whyte, D.S. Peeper, T. Jacks, and R.A. Weinberg. 1993. Cell cycle specific association of E2F with the p130 ElA-binding protein. Genes \& Dev. 7: 2392-2404.

Dalton, S. 1992. Cell cycle regulation of the human cdc2 gene. EMBO 1. 11: 1797-1804.

Devoto, S.H., M. Mudryi, J. Pines, T. Hunter, and J.R. Nevins. 1992. A cyclin A protein kinase complex possesses sequence specific DNA binding activity; p33cdk2 is a component of the E2F-cyclin A complex. Cell 68: 167-176.

Dyson, N., M. Dembski, A. Fattaey, C. Ngwu, M. Ewen, and K. Helin. 1993. Analysis of p107-associated proteins: pl07 associates with a form of E2F that differs from $\mathrm{pRb}$-Associated E2F-1. J. Virol. 67: 7641-7647.

Ewen, M.E., H.K. Sluss, L.L. Whitehouse, and D.M. Livingston. 1993. TGF- $\beta$ Inhibition of cdk4 synthesis is linked to cell cycle arrest. Cell 74: 1009-1020

Faha, B., M. Ewen, L. Tsai, D.M. Livingston, and E. Harlow. 1992. Interaction between human cyclin A and adenovirus E1A-associated p107 protein. Science 255: 87-90.

Girling, R., J.F. Partridge, L.R. Bandara, N. Burden, N.F. Totty, J.J. Hsuan, and N.B. La Thangue. 1993. A new component of the transcription factor DRTF1/E2F 1. Nature 362: 83-87.

Gorman, C.M., L.F. Moffat, and B.H. Howard. 1982. Recombinant genomes which express chloramphenicol acetyltransferase in mammalian cells. Mol. Cell. Biol. 2: 1044-1051.

Hamel, P.A., R.M. Gill, R.A. Phillips, and B.L. Gallie. 1992. Transcriptional repression of the E2-containing promoters EIIaE, c-myc, and RBl by the product of the RBl gene. Mol. Cell. Biol. 12: 3431-3438.

Harlow, E. and D. Lane. 1988. Antibodies: A laboratory manual. Cold Spring Harbor Laboratory, Cold Spring Harbor, New York.

Helin, K., J.A. Lees, M. Vidal, N. Dyson, E. Harlow, and A. Fattaey. 1992. A cDNA encoding a pRB-binding protein with properties of the transcription factor E2F. Cell 70: 337-350.

Helin, K., C.L. Wu, A.R. Fattaey, J.A. Lees, B.D. Dynlacht, C. $\mathrm{Ngwu}$, and E. Harlow. 1993. Heterodimerization of the transcription factors E2F-1 and DP-1 leads to cooperative transactivation. Genes \& Dev. 7: 1850-1861.

Herber, B., M. Truss, M. Beato, and R. Muller. 1994. Inducible regulatory elements in the human cyclin $\mathrm{D} 1$ promoter. Oncogene 9: 1295-1304.

Hiebert, S.W., M. Lipp, and J.R. Nevins. 1989. ElA-dependent trans-activation of the human MYC promoter is mediated by the E2F factor. Proc. Natl. Acad. Sci. 86: 3594-3598.

Hiebert, S.W., M. Blake, J. Azizkhan, and J.R. Nevins. 1991. Role of E2F transcription factor in ElA-mediated transactivation of cellular genes. I. Virol. 65: 3547-3552.

Hiebert, S.W., S.P. Chellappan, J.M. Horowitz, and J.R. Nevins. 1992. The interaction of RB with E2F coincides with an inhibition of the transcriptional activity of E2F. Genes \& Dev. 6: 177-185.

Huber, H.E., G. Edwards, P.J. Goodhart, D.R. Patrick, P.S. Huang, M. Ivey-Hoyle, S.F. Barnett, A. Oliff, and D.C. Heimbrook. 1993. Transcription factor E2F binds DNA as a heterodimer. Proc. Natl. Acad. Sci. 90: 3525-3529.

Ivey-Hoyle, M., R. Conroy, H. Huber, P.J. Goodhart, A. Oliff, and D.C. Heimbrook. 1993. Cloning and characterization of E2F-2, a novel protein with the biochemical properties of transcription factor E2F. Mol. Cell. Biol. 13: 7802-7812.

Johnson, C.V., R.H. Singer, and J.B. Lawrence. 1991. Fluorescent detection of nuclear RNA and DNA: Implications for genome organization. In Methods in cell biology led. W. Miller), vol. 35, pp. 73-99. Academic Press, San Diego, CA.

Kaelin, W.G., D.C. Pallas, J.A. DeCaprio, F.J. Kaye, and D.M. Livingston. 1991. Identification of cellular proteins that can interact specifically with the T/E1A-binding region of the retinoblastoma gene product. Cell 64: 521-532.

Kaelin, W.G.J., W. Krek, W.R. Sellers, J.A. DeCaprio, F. Ajchenbaum, C.S. Fuchs, T. Chittenden, Y. Li, P.J. Farnham, M.A. Blanar, D.M. Livingston, and E.K. Flemington. 1992. Expression cloning of a cDNA encoding a retinoblastoma-binding protein with E2F-like properties. Cell 70: 351-364.

Kovesdi, I., R. Reichel, and J.R. Nevins. 1986. Identification of a cellular transcription factor involved in E1A trans-activation. Cell 45: 219-228.

Krek, W., D.M. Livingston, and S. Shirodkar. 1993. Binding to DNA and the retinoblastoma gene product by complex formation of different E2F family members. Science 262: 15571560.

Krek, W., M.E. Ewen, S. Shirodkar, Z. Arany, W.G. Kaelin Jr., and D.M. Livingston. 1994. Negative regulation of the growth-promoting transcription factor E2F-1 by a stably bound cyclin A-dependent protein kinase. Cell 78: 161-172.

Laborda, J. 1991. 36B4 cDNA used as an estradiol-independent mRNA control is the cDNA for human acidic ribosomal phosphoprotein PO. Nucleic Acids Res. 19: 3998.

La Thangue, N.B. 1994. DRTF1/E2F: An expanding family of heterodimeric transcription factors implicated in cell-cycle control. Trends Biochem. Sci. 19: 108-114.

Lam, E.W.-F. and R.J. Watson. 1993. An E2F-binding site mediates cell-cycle regulated repression of mouse B-myb transcription. EMBO I. 12: 2705-2713.

Lawrence, J.B., R.H. Singer, and J.A. McNeil. 1990. Interphase and metaphase resolution of different distances within the human dystrophin gene. Science 249: 928-932.

Lees, E., B. Faha, V. Dulic, S.I. Reed, and E. Harlow. 1992. Cyclin $\mathrm{E} / \mathrm{cdk} 2$ and cyclin A/cdk2 kinases associate with p107 and E2F in a temporally distinct manner. Genes \& Dev. 6: 18741885.

Lees, J.A., M. Saito, M. Vidal, M. Valentine, T. Look, E. Harlow, N. Dyson, and K. Helin. 1993. The retinoblastoma protein binds to a family of E2F transcription factors. Mol. Cell. Biol. 13: 7813-7825.

Li, Y., J.E. Slansky, D.J. Myres, N.R. Drinkwater, W.G. Kaelin, and P.J. Farnham. 1994. Cloning, chromosomal location, and characterization of mouse E2F1. Mol. Cell. Biol. 14; 18611869.

Loeken, M.R. and J. Brady. 1989. The adenovirus EIIA enhancer. J. Biol. Chem. 264: 6572-6579.

Ludlow, J.W., J.A. DeCaprio, C.-M. Huang, W.-H. Lee, E. Paucha, and D.M. Livingston. 1989. SV40 Large T antigen binds preferentially to an underphosphorylated member of the retinoblastoma susceptibility gene product family. Cell 56: 57-65.

Means, A.L., J.E. Slansky, S.L. McMahon, M.W. Knuth, and P.J. Farnham. 1992. The HIPl binding site is required for growth regulation of the dihydrofolate reductase gene promoter. Mol. Cell. Biol. 12: 1054-1063.

Moran, E. 1993. DNA tumor virus transforming proteins and the cell cycle. Curr. Opin. Genet. Dev. 3: 63-70.

Morell, V. 1993. The puzzle of the triple repeats. Science 260: 1422-1423.

Mudryj, M., S.W. Hiebert, and J.R. Nevins. 1990. A role for the adenovirus inducible E2F transcription factor in a prolifera- 
tion dependent signal transduction pathway. $E M B O J .9$ : 2179-2184.

Nevins, J.R. 1992. E2F: A link between the Rb tumor supressor protein and viral oncoproteins. Science 258: 424-429.

Pagano, M., G. Draetta, and P. Jansen-Durr. 1992. Association of cdk2 kinase with the transcription factor E2F during S phase. Science 255: 1144-1147.

Pearson, B.E., H.P. Nasheuer, and T.S.F. Wang. 1991. Human DNA polymerase $\alpha$ gene, sequences controlling expression in cycling and serum-stimulated cells. Mol. Cell Biol. 11: 2081-2095.

Phillip, A., A. Schneider, I. Vasrik, K. Finke, Y. Xiong, D. Beach, K. Alitalo, and M. Eilers. 1994. Repression of cyclin D1: A novel function of MYC. Mol. Cell. Biol. 14: 4032-4043.

Qin, X.-Q., T. Chittenden, D.M. Livingston, and W.G. Kaelin. 1992. Identification of a growth suppression domain within the retinoblastoma gene product. Genes \& Dev. 6: 953-964.

Schwarz, J.K., S.H. Devoto, E.J. Smith, S.P. Chellappan, L. Jakoi, and J.R. Nevins. 1993. Interactions of the pl07 and Rb proteins with $\mathrm{E} 2 \mathrm{~F}$ during the cell proliferation response. $E M B O$ J. 12: 1013-1020.

Shan, B., X. Zhu, P.-L. Chen, T. Durfee, Y. Yang, D. Sharp, and W.-H. Lee. 1992. Molecular cloning of cellular genes encoding retinoblastoma-associated proteins: Identification of a gene with properties of the transcription factor E2F. Mol. Cell. Biol. 12: 5620-5631.

Shirodkar, S., M. Ewen, J.A. DeCaprio, J. Morgan, D.M. Livingston, and T. Chittenden. 1992. The transcription factor E2F interacts with the retinoblastoma product and a p107-cyclin A complex in a cell cycle-regulated manner. Cell 68: 157166.

Slansky, J.E., Y. Li, W.G. Kaelin, and P.J. Farnham. 1993. A protein synthesis-dependent increase in E2Fl mRNA correlates with growth regulation of the DHFR promoter. Mol. Cell. Biol. 13: 1610-1618.

Thalmeier, K., H. Synovzik, R. Mertz, E.-L. Winnacker, and M. Lipp. 1989. Nuclear factor E2F mediates basic transcription and trans-activation by E1A of the human MYC promoter. Genes \& Dev. 3: 527-536.

Weintraub, S.J., C.A. Prater, and D.C. Dean. 1992. Retinoblastoma protein switches the E2F site from positive to negative element. Nature 358: 259-261.

Xiao, J.H., I. Davidson, H. Matthes, J. Garnier, and P. Chambon. 1991. Cloning, expression and transcriptional properties of the human enhancer factor TEF-1. Cell 65: 551-568.

Yamamoto, M., M. Yoshida, K. Ono, T. Fujita, N. Ohtani-Fujita, T. Sakai, and T. Nikaido. 1994. Effect of tumor suppressors on cell cycle-regulatory genes: $\mathrm{RB}$ suppresses $\mathrm{p} 34 \mathrm{cdc} 2$ expression and normal p53 suppress cyclin A expression. Exp. Cell. Res. 210: 94-101.

Yee, A.S., R. Reichel, I. Kovesdi, and J.R. Nevins. 1987. Promoter interaction of the E1A-inducible factor E2F and its potential role in the formation of a multi-component complex. EMBO I. 6: 2061-2068.

Yee, A.S., P. Raychaudhuri, L. Jakoi, and J.R. Nevins. 1989. The adenovirus-inducible factor E2F stimulates transcription after specific DNA binding. Mol. Cell. Biol. 9: 578-585.

Zamanian, M. and N.B. La Thangue. 1992. Adenovirus E1A prevents the retinoblastoma gene product from repressing the activity of a cellular transcription factor. $E M B O J$. 11: 2603 2610.

Zhu, L., S. van der Heuvel, K. Helin, A. Fattaey, M. Ewen, D. Livingston, N. Dyson, and E. Harlow. 1993. Inhibition of cell proliferation by p107, a relative of the retinoblastoma protein. Genes \& Dev. 7: 1111-1125. 


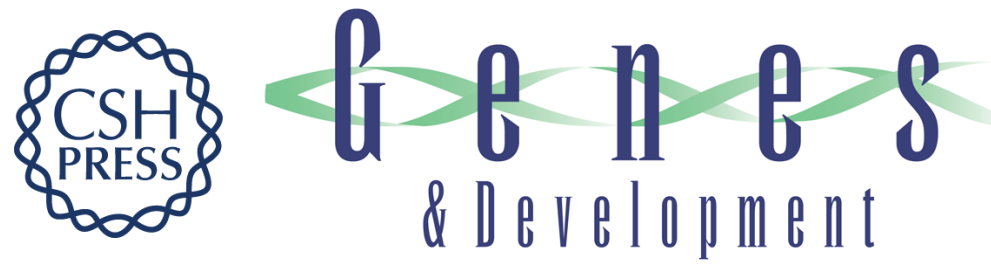

\section{E2F-4, a new member of the E2F transcription factor family, interacts with p107.}

D Ginsberg, G Vairo, T Chittenden, et al.

Genes Dev. 1994, 8:

Access the most recent version at doi:10.1101/gad.8.22.2665

References This article cites 61 articles, 31 of which can be accessed free at:

http://genesdev.cshlp.org/content/8/22/2665.full.html\#ref-list-1

License

Email Alerting

Service

Receive free email alerts when new articles cite this article - sign up in the box at the top right corner of the article or click here.

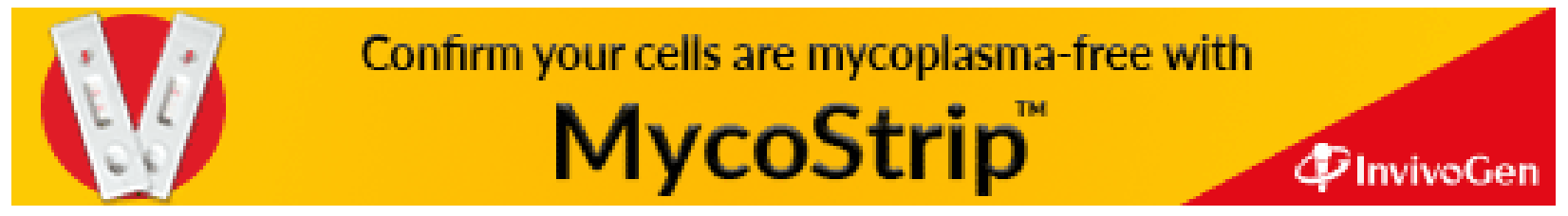

